\title{
Biosynthesis and Isolation of Selenoneine from Genetically Modified Fission Yeast
}

\author{
Nikolaus G. Turrini, ${ }^{\mathrm{a},+}$ Nina Kroepfl, ${ }^{\mathrm{a},{ }^{\dagger}}$ Kenneth B. Jensen, ${ }^{\mathrm{a}}$ Tamara C. Reiter, ${ }^{\mathrm{b}}$ Kevin A. Francesconi, ${ }^{\mathrm{a}}$ \\ Tanja Schwerdtle, ${ }^{c}$ Wolfgang Kroutil ${ }^{b}$ and Doris Kuehnelt ${ }^{a,}{ }^{*}$
}

\begin{abstract}
Selenoneine, a naturally occuring form of selenium, is the selenium analogue of ergothioneine, a sulfur species with health relevance not only as a purported antioxidant but likely also beyond. Selenoneine has been speculated to exhibit similar effects. To study selenoneine's health properties as well as its metabolic transformation, the pure compound is required. Chemical synthesis of selenoneine, however, is challenging and biosynthetic approaches have been sought. We herein report the biosynthesis and isolation of selenoneine from genetically modified fission yeast Schizosaccharomyces pombe grown in a medium containing sodium selenate. After cell lysis and extraction with methanol, selenoneine was purified by three consecutive preparative reversed-phase HPLC steps. The product obtained at the mg level was characterised by high resolution mass spectrometry, NMR as well as HPLC/ICPMS. Biosynthesis was found to be a promising alternative to chemical synthesis, and should be suitable for upscaling to produce higher amounts of this important selenium species in the future.
\end{abstract}

\section{${ }_{1}$ Introduction}

${ }_{2}$ Selenoneine is the selenium analogue of the sulphur metabolite sergothioneine (Fig. 1), a purported anti-oxidant occurring in ${ }^{37}$ ${ }_{4}$ microorganisms, fungi, plants and animals. ${ }^{1}$ Ergothioneine has ${ }_{5}$ recently attracted considerable attention following the report ${ }_{6}$ that it is synthesized by strictly anaerobic bacteria strongly 7suggesting physiological roles beyond its discussed anti- ${ }^{41}$ 8 oxidative potential. ${ }^{1,2}$ Selenoneine, which was first discovered ${ }^{42}$ 9 in marine fish ${ }^{3}$ and later also detected in human blood, ${ }^{4,5}$ is ${ }^{43}$ 10 expected to be of similar importance; it is thought to contribute ${ }_{11}$ significantly to selenium's beneficial health effects, ${ }^{6}$ and might ${ }^{45}$ ${ }_{12}$ also play a role in methyl mercury detoxification. 7,8

${ }_{13}$ To gain further insight into selenoneine's toxicity and protective ${ }_{14}$ effects as well as its metabolic transformation in organisms, the ${ }_{15}$ pure compound needs to be produced. In contrast to ${ }_{16}$ ergothioneine, for which synthetic routes have been ${ }_{17}$ published, ${ }^{9-11}$ the chemical synthesis of selenoneine has been ${ }_{18}$ described only in the form of a patent application exactly ${ }_{19}$ following a protocol published for its sulphur analogue zoergothioneine. ${ }^{12}$ However, our attempts to synthesize ${ }_{21}$ selenoneine following this route were unsuccessful and we 22 sought other possibilities for its production.

${ }_{23}$ Alternatively, selenoneine can be isolated from natural sources ${ }_{24}$ containing sufficient quantities of this selenium species. ${ }_{25}$ Recently, Pluskal et al. engineered fission yeast, ${ }_{26}$ Schizosaccharomyces pombe, to overexpress an enzyme of the 27 biosynthetic pathway leading to ergothioneine and reported 28 that selenoneine was also produced by the organism, when the ${ }_{29}$ growth medium was supplemented with sodium selenate. ${ }^{13}$ The ${ }_{30}$ possible biotechnological production of selenoneine has also ${ }_{31}$ been suggested by a recent patent application. ${ }^{14}$ In the light of ${ }_{32}$ the findings for the genetically modified strain of S. pombe $e^{13}$ and з3 its availability from the Yeast Genetic Resource Center in Osaka,
${ }_{34}$ Japan, we attempted to utilize this microorganism for the ${ }_{35}$ biosynthesis and isolation of selenoneine.<smiles>C[N+](C)(C)C(Cc1cnc([Se])[nH]1)C(=O)[O-]</smiles>

reduced form

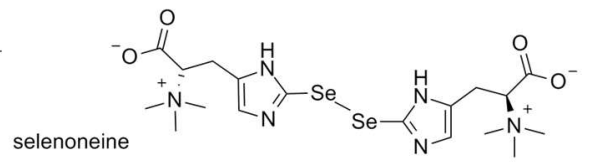

oxidised form<smiles>C[N+](C)(C)[C@H](Cc1c[nH]c(=S)[nH]1)C(=O)[O-]</smiles>

${ }_{48}$ Figure 1: Structures of ergothioneine (bottom) and its selenium analogue selenoneine in 49 its reduced and oxidised form (top)

\footnotetext{
Institute of Chemistry, Analytical Chemistry, NAWI Graz, University of Graz,

Universitaetsplatz 1, 8010 Graz, Austria, email: doris.kuehnelt@uni-graz.at

b. Institute of Chemistry, Organic and Bioorganic Chemistry, NAWI Graz, University

of Graz, Harrachgasse 21/III, 8010 Graz, Austria

c. Institute of Nutritional Science, University of Potsdam, Arthur-Scheunert-Allee

114-116, 14558 Nuthetal, Germany

† These authors contributed equally to this work.
} 


\section{Experimental}

\section{${ }_{2}$ Chemicals and Reagents}

${ }_{3}$ Analytical grade chemicals and purified water (18.2 M $\Omega$, Milli${ }_{4} \mathrm{Q}$, Academic water purification system, Millipore $\mathrm{GmbH}$, ${ }_{5}$ Vienna, Austria) were used for all isolation steps and analyses. ${ }_{6}$ Ammonium formate ( $\left.\geq 95 \%\right)$, formic acid ( $\geq 98 \%$, p.a.), Tris-(27 carboxyethyl)phosphine hydrochloride (TCEP; > 98\%, for 8 biochemistry), nitric acid $(65 \%$, p.a.) and hydrogen peroxide ${ }_{9}(30 \%$, p.a., stabilized) were purchased from Carl Roth $\mathrm{GmbH}+$ ${ }_{10} \mathrm{Co}$. KG (Karlsruhe, Germany). Further purification of nitric acid ${ }_{11}$ was achieved by sub-boiling. Acetic acid (glacial, 100\%, ${ }_{12}$ anhydrous for analysis) and methanol (HPLC gradient grade) ${ }_{13}$ were obtained from Merck (Darmstadt, Germany) and VWR ${ }_{14}$ International (Fontenay-sous-Bois, France), respectively. ${ }_{15}$ Ergothioneine $(\geq 98 \%)$ and $D$, L-selenomethionine ( $>99 \%$ ) were ${ }_{16}$ purchased from Tetrahedron (Paris, France) and Fluka (Buchs, ${ }_{17}$ Switzerland), respectively, and were utilized for the preparation ${ }_{18}$ of stock standard solutions in water stored at $4{ }^{\circ} \mathrm{C}$. Single${ }_{19}$ element standard solutions of selenium (1000 mg Se $\mathrm{L}^{-1} \pm 0.2 \%$ 20 in $2 \% \mathrm{HNO}_{3}$ ) and germanium (1000 $\pm 3 \mathrm{mg} \mathrm{Ge} \mathrm{L}^{-1}$ in $\left.2 \% \mathrm{HNO}_{3}\right)$ ${ }_{21}$ for the determination of total selenium were obtained from Carl ${ }_{22}$ Roth GmbH + Co. KG and CPI International (Santa Rosa, USA), 80 ${ }_{23}$ respectively. Standard solutions for total selenium and ${ }_{81}$ ${ }_{24}$ selenium species determination were prepared fresh daily by ${ }_{25}$ dilution with water from stock standard solutions. Sodium ${ }_{83}$ ${ }_{26}$ selenate $(98 \%)$ for treatment of $S$. pombe was obtained from ${ }_{84}$ ${ }_{27}$ Sigma-Aldrich (Vienna, Austria). Deuterated water $\left(D_{2} \mathrm{O}, 99.95 \%{ }_{85}\right.$ $\left.{ }_{28} \mathrm{D}\right)$ for NMR spectroscopy was purchased from Deutero ${ }_{29}$ (Kastellaun, Germany).

${ }_{30}$ Chemicals for cultures of S. pombe were: Ammonium chloride ${ }_{31}(\geq 99.5 \%$, puriss. p.a.), D-(+)-glucose ( $\geq 99.5 \%), \mathrm{Na}_{2} \mathrm{HPO}_{4}$ ${ }_{32}(\geq 98.0 \%)$, potassium hydrogen phthalate $(\geq 99.5 \%), \mathrm{MgCl}_{2} \cdot{ }_{90}$ ${ }_{33} 6 \mathrm{H}_{2} \mathrm{O}$ ( $\geq 99.0 \%$, BioUltra), $\mathrm{CaCl}_{2} \cdot 2 \mathrm{H}_{2} \mathrm{O}$ (98+\%, A.C.S. reagent ${ }_{91}$ ${ }_{34}$ grade), $\mathrm{KCl}(\geq 99.5 \%), \mathrm{Na}_{2} \mathrm{SO}_{4}\left(\geq 99.0 \%\right.$, BioXtra), $\mathrm{MnSO}_{4} \cdot \mathrm{H}_{2} \mathrm{O}{ }_{92}$ ${ }_{35}\left(\geq 99.0 \%\right.$, ReagentPlus $\left.{ }^{\circledast}\right), \mathrm{KI}\left(\geq 99.5 \%\right.$, BioUltra), $\mathrm{CuSO}_{4} \cdot 5 \mathrm{H}_{2} \mathrm{O}{ }_{93}$ ${ }_{36}\left(\geq 98.0 \%\right.$, Bioreagent), $\mathrm{ZnSO}_{4} \cdot 7 \mathrm{H}_{2} \mathrm{O}$ ( $\geq 99.0 \%$, BioReagent), $\mathrm{FeCl}_{3}$ 37. $6 \mathrm{H}_{2} \mathrm{O}$ (97\%, ACS reagent), boric acid ( $\geq 99.5 \%$, Bioreagent), 95 ${ }_{38}$ citric acid ( $\geq 99.5 \%$, ACS reagent), molybdic acid ( $\geq 85.0 \% \mathrm{MoO}_{3}$ ${ }_{39}$ basis, ACS reagent), Biotin ( $\geq 99 \%$, BioReagent), Inositol ( $\geq 99.0 \%$, 97

${ }_{40}$ Plant Cell Culture Reagent), pantothenic acid (as hemicalcium ${ }_{98} \mathrm{~A}$ Dionex Ultimate 3000 HPLC system (Thermo Scientific, ${ }_{41}$ salt, $\geq 99.0 \%$ ), nicotinic acid ( $\geq 98 \%$, Bioreagent), L-Lysine ( $\geq 98 \%$ ), ${ }_{9}$ Waltham, USA) consisting of a Rapid Separation (RS) pump, an ${ }_{42} \mathrm{~L}$-Leucine ( $\geq 99.5 \%$, BioUltra) and adenine ( $\geq 99 \%$, BioReagent) ${ }_{100} \mathrm{RS}$ autosampler and an RS column compartment connected to ${ }_{43}$ from Sigma-Aldrich; uracil ( $\geq 99 \%$, puriss.) and histidine ( $\geq 99 \%,{ }_{101}$ a Q Exactive Orbitrap Mass Spectrometer (Thermo Scientific) ${ }_{44}$ puriss.) from Fluka.

${ }_{45} \mathrm{YES}$ and EMM2-medium as well as the necessary stock solutions ${ }_{103}$ (Thermo Scientific) was used for identification of selenoneine in ${ }_{46}$ were prepared according to literature. ${ }^{15}$ YPD-medium ( $\mathrm{pH} \mathrm{6.5)}{ }_{104}$ yeast cultures, fractions monitored during the isolation, and the ${ }_{47}$ was prepared by dissolving $10 \mathrm{~g}$ yeast extract (Oxoid L21, ${ }_{105}$ final isolated product. The electrospray ionization source was ${ }_{48}$ Basingstoke, UK), 20 g peptone (Oxoid L37, Basingstoke, UK), ${ }_{106}$ operated in positive mode with the following source settings: ${ }_{49}$ and $20 \mathrm{~g}$ glucose in $1 \mathrm{~L}$ water. Agar $\left(20 \mathrm{~g} \mathrm{~L}^{-1}\right.$, Oxoid LP11, ${ }_{107}$ gas temperature $440{ }^{\circ} \mathrm{C}$, gas flow rates 53 (sheath) and 14 (aux) ${ }_{50}$ Basingstoke, UK) was added to obtain plates.

51

${ }_{52}$ Instrumentation ${ }_{53}$ Sterilised spatula, scalpel and pincers were used for the ${ }^{111} 100-1000$. The automatic gain control (AGC) target and the ${ }_{54}$ preparation of cell cultures. An Eppendorf BioPhotometer plus ${ }^{112}$ maximum injection time (IT) were $3 \times 10^{6}$ and $100 \mathrm{~ms}$, ${ }_{55}$ (Eppendorf, Hamburg, Germany) was employed for optical ${ }_{113}$ respectively. MS/MS (ddMS/MS) was performed with collision ${ }_{56}$ density measurements of yeast cultures at $595 \mathrm{~nm}\left(\mathrm{OD}_{595}\right)$. Cell 114 energies of 10, 20, 30 (stepped) instrument units for the ${ }_{57}$ lysis was achieved using a Branson Digital Sonifier (Branson, ${ }_{15}$ precursor ion at $\mathrm{m} / \mathrm{z} 553$. Settings for MS/MS were as follows:
${ }_{58}$ Danbury, USA). Isolation of selenoneine from S. pombe was 59 carried out on an Agilent 1100 high performance liquid Waldbronn, Germany) consisting of a binary pump (G1312A), a thermostated autosampler (G1329A) equipped with an (G1315B), and a 1200 series preparative fraction collector ieved by splitting ca. $4 \%$ of the chromatographic flow via a fraction collector to an Agilent 7500ce inductively coupled plasma mass spectrometer (ICPMS, Agilent Technologies) Research International, Berkshire, UK), a cyclone spray
Rest with a Burgener Ari Mist HP nebulizer (Burgener cell. The ICPMS was of sulphur and selenium species at $\mathrm{m} / \mathrm{z} 34,77$ and 78 . The combined fractions were evaporated to dryness after each clean-up step with a Rotary Evaporator (RV 10 digital, IKA Works 105 T - 10 ef diaphragm vacuum pump (Welch by Gardner .

$\mathrm{GmbH}$, Leutkirch, Germany) was used for microwave-assisted cid digestion before determination of total selenium in the selenium determination and final characterisation of selenium ${ }_{86}$ ICP-QQQ-MS operated in $\mathrm{H}_{2}$-mode $\left(\mathrm{H}_{2}\right.$ flow rate: $\left.3.5 \mathrm{~mL} \mathrm{~min}{ }^{-1}\right)$ s7 equipped with a Micro Mist nebulizer and a Scott-type spray chamber, either using an ASX-500 series ICP-MS autosampler or an Agilent 1100 HPLC system including a degasser (G1379A), a and a thermostated column compartment (G1316A) for sample introduction during total selenium or selenium species determination, respectively. Monitored masses were $m / z 77$, $\mathrm{CO}_{2}$ in $\mathrm{Ar}$ as optional gas at a flow rate of $12 \%$ of the carrier gas 108instrument units, spray voltage $3500 \mathrm{~V}$ and capillary 109 temperature $270{ }^{\circ} \mathrm{C}$. A resolution of 70,000 (full width half ${ }_{110}$ maximum, FWHM) was used for a full scan range of $\mathrm{m} / \mathrm{z}$ (G1364B). Monitoring of selenium species in yeast cultures was 
1 resolution 17,500 FWHM, maximum IT 50 ms, AGC target $1 \times 55$ ${ }_{2} 10^{5}$ and isolation window 8 Thomson (mass/charge).

${ }_{3} \mathrm{NMR}$ spectra were measured on a Bruker Avance III $500 \mathrm{MHz}$ ${ }_{4} \mathrm{NMR}$ spectrometer, equipped with a $5 \mathrm{~mm}$ TXI probe with z-axis 58 ${ }_{5}$ gradients. Chemical shifts are reported in $\mathrm{ppm}(\delta)$, with the 59 ${ }_{6}$ Solvent reference relative to TMS $(\delta=0.00 \mathrm{ppm})$ as an internal 60 7standard $\left(\mathrm{D}_{2} \mathrm{O}, \delta=4.79 \mathrm{ppm}\right)$; coupling constants $J$ are given in 61 ${ }_{8} \mathrm{~Hz}$.

\section{${ }_{10}$ Culturing of S. pombe TP1803}

${ }_{11}$ S. pombe TP1803 cells on sterile filter paper were purchased ${ }_{12}$ from the Yeast Genetic Resource Center (YGRC), Osaka, Japan. 65 ${ }_{13}$ Part of the yeast was cut from the "pellet" and a streak on a YES${ }_{14}$ agar-plate was made. The streak was incubated at $30{ }^{\circ} \mathrm{C}$ for 2 ${ }_{15}$ days. Overnight cultures (ONCs, $10 \mathrm{~mL}$ each) were prepared in ${ }_{16} \mathrm{EMM} 2$-medium in $50 \mathrm{~mL}$ polypropylene tubes and grown in the ${ }_{17}$ shaker at $28{ }^{\circ} \mathrm{C}$ and $140 \mathrm{rpm}$. The ONCs were used to inoculate ${ }_{18}$ the main cultures. These were prepared in EMM2-medium (300 ${ }_{19} \mathrm{~mL}$ in baffled $1 \mathrm{~L}$ flasks, containing $10 \mu \mathrm{M}$ sodium selenate), ${ }_{20}$ which were grown in the shaker at $26^{\circ} \mathrm{C}$ and $120 \mathrm{rpm}$. Another 71 ${ }_{21}$ aliquot of sodium selenate ( $300 \mu \mathrm{L}$ of a $10 \mathrm{mM}$ solution in water) ${ }_{22}$ was supplemented after a reaction time of 48 hours. The ${ }_{23}$ experimental design is shown in Fig. 2. To monitor cell growth, ${ }_{24} \mathrm{OD}_{595}$ of the pre- and main cultures was measured against 74 ${ }_{25} \mathrm{EMM} 2$-medium.

26

\section{${ }_{27}$ Harvesting of S. pombe TP1803}

${ }_{28}$ Harvesting of the cells was performed using a procedure 29 adopted from Pluskal et al. ${ }^{13}$ (Fig. 2). On day 5 after the 78 soinoculation of the main culture, the cells were separated from ${ }_{31}$ the medium by centrifugation $\left(6000 \mathrm{~g}, 20 \mathrm{~min}, 4^{\circ} \mathrm{C}\right)$. The media ${ }_{32}$ were removed; the cell pellets were re-suspended in $20 \mathrm{~mL}{ }^{80}$ ${ }_{33}$ methanol each and sonicated ( $50 \%$ amplitude, $5 \mathrm{~min}$, $2 \mathrm{~s}$ pulse ${ }_{81} 5 \mu \mathrm{m}$ RFICTM column $(3 \times 150 \mathrm{~mm}$, Thermo Scientific) with $5 \mathrm{mM}$ ${ }_{34} \mathrm{On}, 4 \mathrm{~s}$ pulse off). The suspensions were centrifuged $\left(4000 \mathrm{~g}, 20{ }_{82}\right.$ malonate at $\mathrm{pH} 9.5$ as the mobile phase, a flow rate of $0.7 \mathrm{~mL} \mathrm{~min}{ }^{-1}$, ${ }_{35} \mathrm{~min}, 4{ }^{\circ} \mathrm{C}$ ) and the supernatants were evaporated. The residues 83 a column temperature of $40^{\circ} \mathrm{C}$ and an injection volume of $1 \mu \mathrm{L}$. The ${ }_{36}$ from evaporation were taken up in $5 \mathrm{~mL}$ water each and filtered ${ }_{84}$ analytical columns were protected by their respective guard ${ }_{37}$ into HPLC vials through nylon syringe filters (CHROMAFIL ${ }^{\circledR} \mathrm{PA}, 85$ columns.

${ }_{38} 0.20 \mu \mathrm{M}$, Macherey-Nagel, Germany) pre-washed twice with ${ }_{86}$ 39 methanol and twice with water.

40

\section{${ }_{41}$ Total selenium and selenium speciation in S. pombe TP1803}

${ }_{42}$ The distribution of selenium between culture medium, cell ${ }_{43}$ lysate and cell pellet after harvesting was estimated in selected ${ }_{44}$ samples by subjecting $1 \mathrm{~mL}$ of medium, $20 \mu \mathrm{L}$ of cell lysate, or 1 ${ }_{45} \mathrm{~mL}$ of a suspension of the cell pellet in $20 \mathrm{~mL}$ water to ${ }_{46}$ microwave-assisted acid digestion with $5 \mathrm{~mL}$ of nitric acid. ${ }_{47}$ Digests were made up to $50 \mathrm{~mL}$ with water and total selenium 48 was determined by ICPMS using external calibration and Ge as ${ }_{49}$ internal standard.

${ }_{50}$ Selenium speciation in the re-dissolved residues was monitored ${ }_{51}$ by reversed phase HPLC/ICPMS (for experimental conditions ${ }_{52}$ see Supplementary Material Table S-1, HPLC conditions A.1). ${ }_{53}$ The presence of selenate was investigated by anion-exchange ${ }_{54} \mathrm{HPLC} / \mathrm{ICPMS}$ using a Dionex IonPac ${ }^{\mathrm{TM}}$ AS14A-

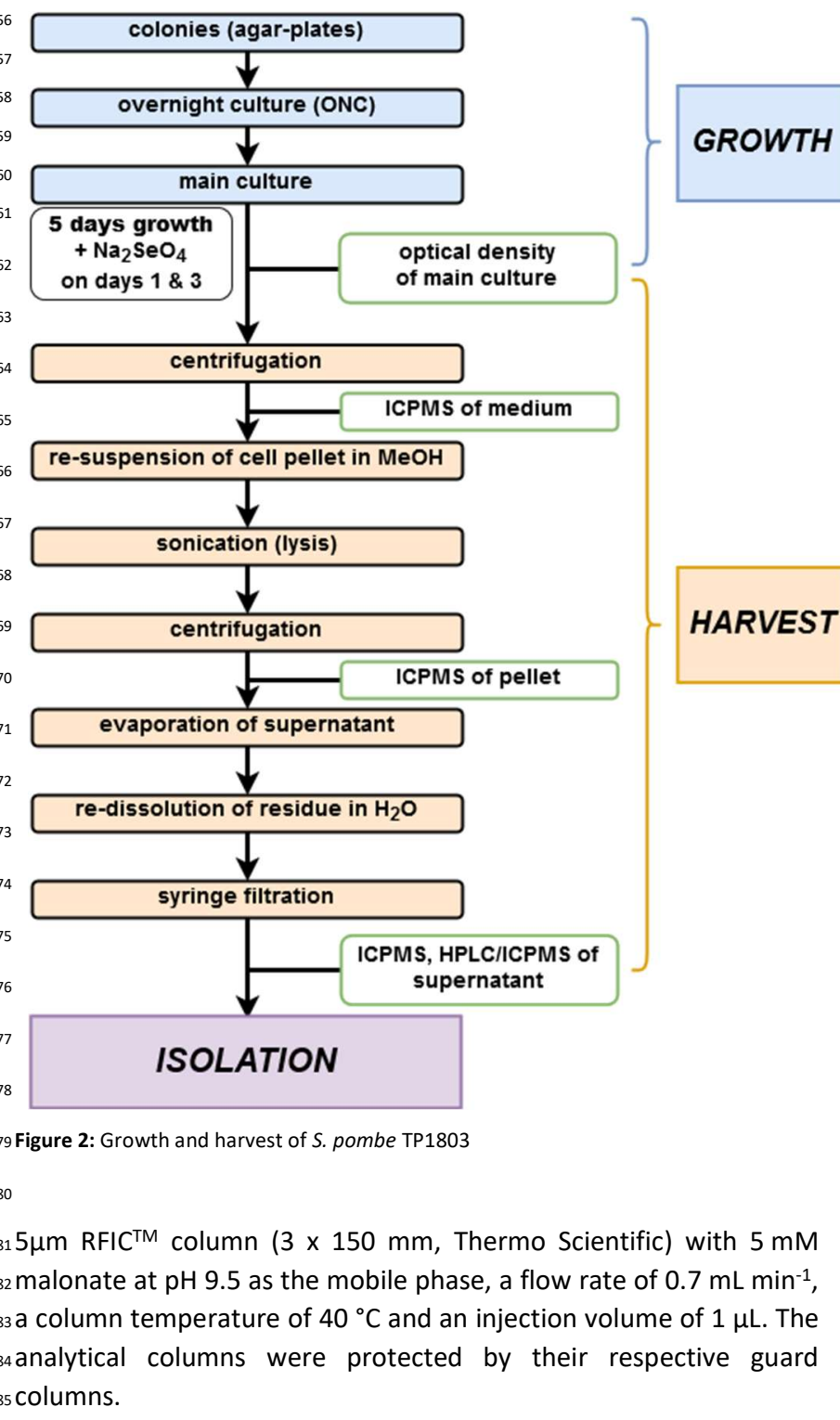

${ }_{87}$ Isolation of selenoneine from cell lysates of S. pombe TP1803

${ }_{88}$ Selenoneine from the lysates of $S$. pombe was isolated by ${ }_{89}$ preparative reversed-phase HPLC in three consecutive steps ${ }_{90}$ (NEUTRAL 1, ACIDIC and NEUTRAL 2; Fig. 3; for experimental ${ }_{91}$ conditions see Supplementary Material Table S-1, B). Collection 92 of fractions was monitored by UV absorbance. During the first ${ }_{93}$ clean-up step (NEUTRAL 1, Fig. 3), part of the effluent from the ${ }_{94}$ column was directed via a T-piece, installed between the diode 95 array detector and the preparative fraction collector, to an ${ }_{96}$ ICPMS to monitor profiles of selenium and sulphur. ${ }_{97}$ Furthermore, $1.5 \%$ aqueous $\mathrm{H}_{2} \mathrm{O}_{2}(1000 \mu \mathrm{L})$ was injected ${ }_{98}$ between the cell lysates to support oxidative conditions in the ${ }_{99} \mathrm{LC}$ to promote the presence of the oxidised form of 00 selenoneine. 


\section{3}

${ }_{2}$ Selenoneine isolated by preparative reversed-phase HPLC was ${ }^{54}$ ${ }_{3}$ characterised by HPLC/ICPMS, high resolution Orbitrap MS and 55 ${ }_{4} \mathrm{NMR}$ spectroscopy. Total selenium in the isolated product was ${ }^{56}$ ${ }_{5}$ determined by ICPMS after dissolution in water and subsequent ${ }^{57}$ ${ }_{6}$ microwave-assisted acid digestion with nitric acid as detailed ${ }^{58}$ 7above. For characterisation by HPLC/ICPMS two 59 ${ }_{8}$ chromatographic conditions differing in the $\mathrm{pH}$ of the mobile ${ }_{60}$ gphase were used (for experimental conditions see ${ }_{10}$ Supplementary Material Table S-1, conditions A.2). ${ }^{61}$ ${ }_{11}$ Quantification of isolated selenoneine was performed using 62 ${ }_{12}$ selenomethionine standards, assuming similar instrument ${ }_{13}$ response for both selenium species. The same chromatographic ${ }_{14}$ conditions were also used for the characterisation of isolated ${ }^{64}$ ${ }_{15}$ selenoneine by HPLC coupled to high resolution Orbitrap MS. 65 ${ }_{16}$ Additionally, flow injection into 3\% aqueous methanol (flow ${ }_{17}$ rate $0.4 \mathrm{~mL} \mathrm{~min}^{-1}$ ) was performed to detect potential impurities. ${ }_{18}$ To check for contamination by selenate the isolated 67 19selenoneine was dissolved in water and subjected to anion- 68 zoexchange HPLC/ICPMS under the conditions described before. ${ }_{21}$ For characterisation by NMR spectroscopy the isolated, dry ${ }_{22}$ selenoneine was re-dissolved in $\mathrm{D}_{2} \mathrm{O}$.

\section{${ }_{23}$ Results and discussion}

${ }_{24}$ Biosynthesis of selenoneine in S. pombe TP1803

${ }_{25}$ While being a cheap selenium donor, sodium selenate was ${ }_{26}$ reported to be toxic to the cells in concentrations higher than ${ }^{78}$ ${ }_{27} 10 \mu \mathrm{M} .{ }^{13}$ Being limited to this maximum concentration, we ${ }^{79} \mathrm{~S}-1$. Selenate was not detectable in the lysates by anion28 conducted a time study to monitor the consumption of selenate 80 exchange HPLC/ICPMS (Supplementary Material Fig. S-2). ${ }_{29}$ from the culture medium. ICPMS measurements revealed that 81 30the selenium added to the medium was consumed almost 82 Isolation and clean-up of selenoneine from S. pombe TP1803 ${ }_{31}$ completely within two days (less than $10 \%$ of the added $\mathrm{Se}{ }_{83} \mathrm{~A}$ crucial step in the clean-up of selenoneine was its separation ${ }_{32}$ remaining in the medium). As the cells were growing for up to $5{ }_{84}$ from its sulphur analogue ergothioneine. Selenoneine and ${ }_{33}$ days, we added another aliquot of sodium selenate after two ${ }_{85}$ ergothioneine only differ by one heteroatom and are, hence, ${ }_{34}$ days thereby avoiding toxic concentrations of selenate while ${ }_{86}$ expected to elute at similar chromatographic retention times. ${ }_{35}$ increasing the amount of selenoneine formed by the ${ }_{87}$ As selenol groups are more readily oxidised than are thiol ${ }_{36}$ microorganism. ${ }_{88}$ groups $^{16}$ we aimed to selectively oxidise selenoneine to achieve ${ }_{37}$ After five days of growth, the medium was removed and the ${ }_{89} \mathrm{a}$ chromatographic behaviour different from that of 38 cells were lysed and extracted with methanol. Determination of $9_{0}$ ergothioneine.

${ }_{39}$ total selenium in the cell culture medium, cell pellet, and cell ${ }_{91}$ However, analytical reversed-phase HPLC/ICPMS coupled to ${ }_{40}$ lysate revealed that only about $5 \%$ of the added selenium had ${ }_{92}$ elemental or high resolution MS using a chromatographic ${ }_{41}$ remained in the medium, whereas ca $25 \%$ could be found in the ${ }_{93}$ system routinely applied in our lab for the separation of ${ }_{42}$ pellet and about $50 \%$ was detected in the lysate (overall ${ }_{94}$ organoselenium species including selenoneine ${ }^{17,18}$ revealed ${ }_{43}$ recovery ca $80 \%$ of the added selenium).

${ }_{95}$ that the oxidised form of selenoneine eluted only marginally ${ }_{44}$ After evaporation of the methanol from the cell lysate, we ${ }_{96}$ later than the reduced form as shown below (see ${ }_{45}$ obtained a yellow oily residue containing the desired product ${ }_{97}$ "Characterisation of selenoneine isolated from $S$. pombe ${ }_{46}$ selenoneine along with its sulphur analogue ergothioneine and ${ }_{98}$ TP1803"). When the mobile phase (20 mM ammonium formate ${ }_{47}$ other matrix constituents. Based on selenium speciation ${ }_{99} 3 \%$ methanol pH 3.0) was changed to $3 \%$ aqueous methanol, the ${ }_{48}$ analysis by reversed-phase HPLC/ICPMS after re-dissolution in ${ }_{100}$ oxidised form of selenoneine was shifted towards longer ${ }_{49}$ water we estimated that $300 \mathrm{~mL}$ of culture yielded about $180 \mu \mathrm{g}{ }_{101}$ retention times, whereas the reduced form still eluted close to ${ }_{50} \mathrm{Se}$ in the form of selenoneine (sum of reduced and oxidised ${ }_{102}$ ergothioneine (Supplementary Material Fig. S-3). Although ${ }_{51}$ form) along with other minor selenium species. A typical ${ }_{103}$ column recoveries were only around $70 \%$, we decided to ${ }_{52}$ chromatogram is shown in Supplementary Material Fig. ${ }_{104}$ proceed with this mobile phase as it can be easily removed by 105 evaporation when clean-up by preparative chromatography is 106 employed. 
${ }_{1}$ For the oxidation of selenoneine in the lysates of $S$. pombe we ${ }_{58}$ Multiple Bond Correlation $(\mathrm{HMBC})$ between ${ }^{13} \mathrm{C}$ and ${ }^{1} \mathrm{H}$ 2 aimed to avoid complex and time-consuming procedures like ${ }_{59}$ (Supplementary Material Fig. S-10c).

3treatment with organic solvents followed by evaporation to ${ }_{60}$ High resolution Orbitrap MS showed a clean spectrum for ${ }_{4}$ dryness as previously suggested. ${ }^{3}$ Preliminary investigations ${ }_{61}$ selenoneine with masses corresponding to the protonated ${ }_{5}$ using oxidation by addition of aqueous $\mathrm{H}_{2} \mathrm{O}_{2}$ at different ${ }_{62}$ molecule, its doubly-charged species, as well as their sodium ${ }_{6}$ concentrations resulted in the degradation of selenoneine as ${ }_{3}$ and potassium adducts (Fig. 4). The structure was confirmed by 7 well as the formation of mixed selenium-sulphur species and ${ }_{64}$ fragmentation (Fig. 4).

${ }_{8}$ oxidised ergothioneine (Supplementary Material Fig. S-4). We ${ }_{65} \mathrm{HPLC} / \mathrm{ICPMS}$ of an aqueous solution of the isolated compound ${ }_{9}$ noticed, however, that regular rinsing of the LC system with ${ }_{66}$ was employed to exclude the presence of selenium-containing ${ }_{10} 0.3 \% \mathrm{H}_{2} \mathrm{O}_{2}$ (Supplementary Material Fig. S-5) as well as freezing 67 contaminations. Reversed-phase chromatography with $3 \%$ ${ }_{11}$ and thawing of the lysates led to a higher ratio of oxidised to ${ }_{68}$ aqueous methanol as mobile phase showed an intense signal at ${ }_{12}$ reduced selenoneine without the undesired by-products that ${ }_{6}$ the retention time of oxidised selenoneine and a second albeit ${ }_{13}$ had formed when $\mathrm{H}_{2} \mathrm{O}_{2}$ was added directly to the samples. 70 smaller signal at the retention time of its reduced form, ${ }_{14}$ Hence, we decided to apply those mild and straight-forward ${ }_{71}$ whereby the baseline of the chromatogram did not return to 15 methods, although quantitative oxidation was not always 72 background levels between the two peaks (Supplementary 16 achieved.

${ }_{73}$ Material Fig. S-11a). This pattern of chromatographic peaks ${ }_{17}$ Transfer of the analytical reversed-phase HPLC separation ${ }_{74}$ persisted when the $\mathrm{pH}$ of the mobile phase was decreased to ${ }_{18} \mathrm{employing} 3 \%$ aqueous methanol as the mobile phase to the 753.0 , although the signal of the oxidised form was shifted to 19 preparative scale resulted in a broad signal for oxidised 76 lower retention times (Supplementary Material Fig. S-11b). 20 selenoneine (Supplementary Material Fig. S-5b). Applying a ${ }_{77} \mathrm{HPLC} /$ Orbitrap MS experiments under the same ${ }_{21}$ methanol gradient improved the peak shape and concurrently $78 \mathrm{chromatographic} \mathrm{conditions} \mathrm{(Supplementary} \mathrm{Material} \mathrm{Fig.} \mathrm{S-12)}$ 22 ensured the removal of late eluting sample constituents from 79 indicated that besides in-source reduction/oxidation of ${ }_{23}$ the column before injection of the next sample (Supplementary 80 selenoneine, an equilibrium between the reduced and the ${ }_{24}$ Material Fig. S-6). In this way, fractions of S. pombe lysates 81 oxidised selenoneine existed on the column confirming the 25 containing the oxidised form of selenoneine were collected and 82 unusual peak shape found in HPLC/ICPMS. Addition of TCEP to ${ }_{26}$ evaporated to dryness (preparative HPLC, NEUTRAL 1, Fig. 3). 83 the mobile phase resulted in reduction of selenoneine leading ${ }_{27}$ Although HPLC/ICPMS monitoring of the residue re-dissolved in 84 to a single peak with improved peak shape (Supplementary ${ }_{28}$ water indicated selenium purity as well as the absence of ${ }_{85}$ Material Fig. S-13). Under these conditions the recovery of ${ }_{29}$ Sulphur species like ergothioneine (Supplementary Material Fig. ${ }_{86}$ selenoneine when quantified against selenomethionine ${ }_{30} \mathrm{~S}-7$ ), recording of the corresponding UV signal showed the ${ }_{87}$ standard solutions in comparison to total selenium was found ${ }_{31}$ presence of non-selenium containing matrix constituents in the 88 to be $108 \pm 1 \%$. The selenium purity was $\geq 98 \%$.

${ }_{32}$ collected fraction (Supplementary Material Fig. S-8a). High ${ }_{89}$ As determined from total selenium measurements of the final ${ }_{33}$ resolution MS of the re-dissolved fraction also indicated 90 product, we succeeded in isolating about $700 \mu \mathrm{g}$ of oxidised 34 impurities (Supplementary Material Fig. S-9a). ${ }_{91}$ selenoneine from $1 \mathrm{~L}$ of original cell culture (mean $\mathrm{OD}_{595} 9.5 \pm$ ${ }_{35}$ Hence, a second clean-up step was applied, whereby the $\mathrm{pH}$ of ${ }_{92} 1.6$ corresponding to ca. $1.5 \times 10^{11}$ cells $\left.{ }^{19}\right)$. When comparing the ${ }_{36}$ the mobile phase was decreased again by the addition of acetic ${ }_{93}$ sum of reduced and oxidised selenoneine determined in the ${ }_{37}$ acid (preparative HPLC, ACIDIC, Fig. 3). Monitoring of the UV ${ }_{94}$ lysates by HPLC/ICPMS with the total selenium concentration ${ }_{38}$ trace (Supplementary Material Fig. S-8b) as well as high ${ }_{95}$ after isolation, the isolation yield was about $35 \%$.

39 resolution MS (Supplementary Material Fig. S-9b) indicated 40 efficient clean up. However, NMR (500 MHz) analysis of the ${ }_{41}$ selenoneine-containing fraction revealed that the oxidised ${ }_{42}$ selenoneine was in the form of the acetate (data not shown). ${ }_{43}$ Therefore, another preparative clean-up step at neutral $\mathrm{pH}$ was ${ }_{44}$ employed (preparative HPLC, NEUTRAL 2, Fig. 3; Supplementary ${ }_{45}$ Material Fig. S-8c).

46

\section{${ }_{47}$ Characterisation of selenoneine isolated from S. pombe TP1803}

\section{${ }_{96}$ Conclusions}

${ }_{97}$ The successful isolation of the oxidised form of selenoneine ${ }_{98}$ from genetically modified S. pombe opens up a broad field of ${ }_{99}$ future applications such as its use as a standard compound for 100 its analysis as well as its toxicological and metabolic 101 characterisation. Such investigations will help to increase our 102 understanding of selenoneine's role and health effects, and

${ }_{48}$ The oxidised selenoneine collected from the third preparative 103 indicate its potential usefulness as a food supplement or ${ }_{49}$ chromatographic step (preparative HPLC, NEUTRAL 2, Fig. 3) ${ }_{104}$ therapeutic agent.

5owas characterised by NMR, high resolution $M S$, and ${ }_{51} \mathrm{HPLC} / \mathrm{ICPMS}$. The proton NMR spectrum (500 $\mathrm{MHz}$ ) yielded ${ }_{52}$ signals corresponding to those obtained after isolation from ${ }^{105}$ Conflicts of interest

${ }_{53}$ tuna blood ${ }^{3}$ but without the impurities observed when ${ }_{106}$ There are no conflicts to declare. ${ }_{54}$ selenoneine was purified from the fish matrix (Supplementary ${ }_{55}$ Material Fig. S-10a). Furthermore, the structure was confirmed ${ }_{56}$ by Heteronuclear Single Quantum Coherence Spectroscopy ${ }_{57}$ (HSQC) (Supplementary Material Fig. S-10b) and Heteronuclear 

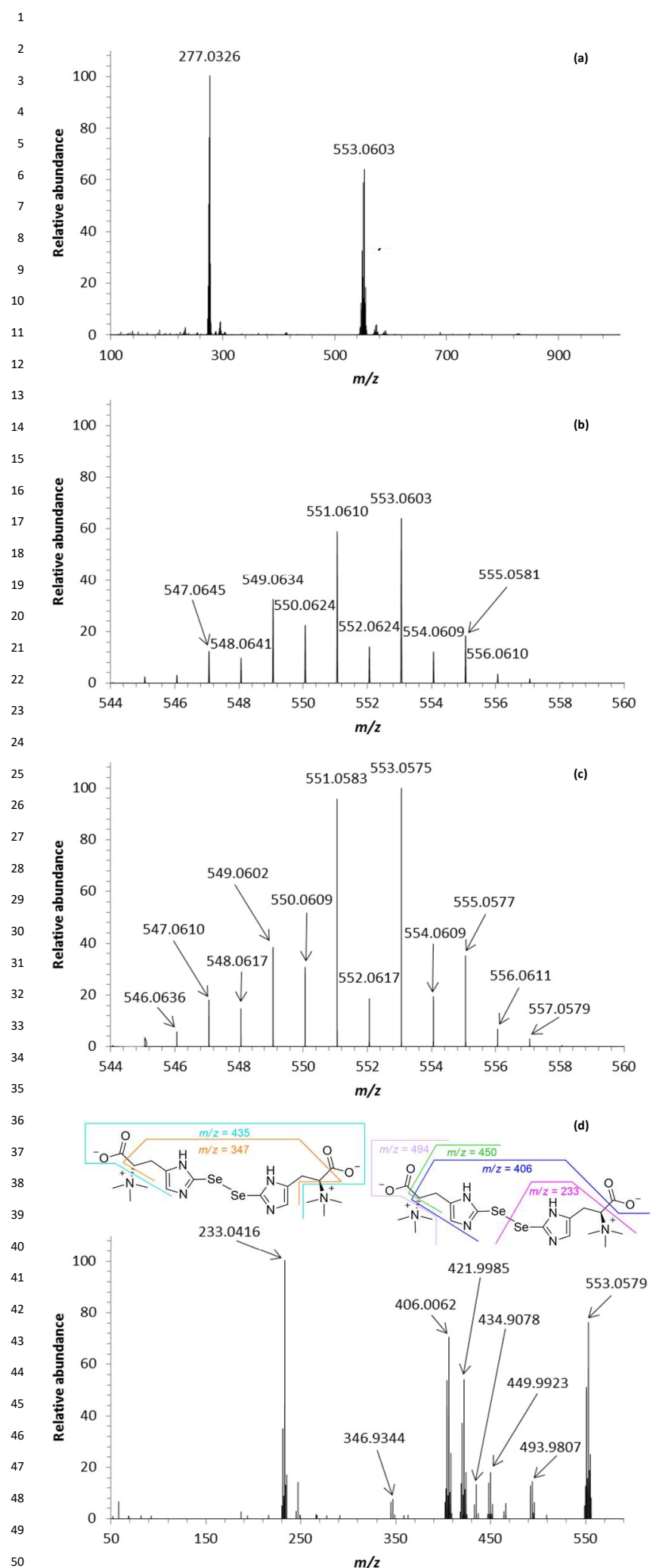

51 Figure 4: Flow injection ESI-Orbitrap-MS of the cleaned-up oxidised selenoneine isolated 52 from a lysate of $S$. pombe grown in selenate containing medium (a) spectrum of oxidised 1151 53 selenoneine, (b) zoom of the measured isotope pattern for oxidised selenoneine (c) 116 54 calculated isotope pattern for oxidised selenoneine, (d) fragmentation of $m / z 553.0603117$ 55 (the signal at $m / z 422$ remained unassigned but was suspected to be the oxide of $m / z_{119}^{118}$ 56406); mobile phase: $3 \%$ aqueous methanol; flow rate: $0.4 \mathrm{~mL} \mathrm{~min}{ }^{-1}$, injection volume: 112014 $57 \mu \mathrm{L}$.

\section{${ }_{59}$ Acknowledgements}

${ }_{60}$ The authors thank the Austrian Science Fund (FWF, project ${ }_{61}$ number I 2262-N28) and the "Deutsche Forschungs${ }_{62}$ gemeinschaft" (DFG, project grant number SCHW 903/9-1) for ${ }_{63}$ funding this research. We acknowledge Tomáš Pluskal and the ${ }_{64}$ Yeast Genetic Resource Center (YGRC), Osaka, Japan, for ${ }_{65}$ providing S. pombe TP1803. We thank Klaus Zangger for NMR ${ }_{66}$ Spectra and the NAWI Graz Central Lab - Metabolomics for ${ }_{67}$ support with the Orbitrap measurements.

\section{${ }_{68}$ References}

${ }_{69} 1$ R. Burn, L. Misson, M. Meury and F.P. Seebeck, Anaerobic origin of ergothioneine, Angew. Chem. Int. Ed., 2017, 56, 12508-12511.

722 M.W. Ruszczycky and H.-W. Liu, The surprising history of an antioxidant, Nature, 2017, 551, 37-38.

743 Y. Yamashita and M. Yamashita, Identification of a novel selenium-containing compound, selenoneine, as the predominant chemical form of organic selenium in the blood of bluefin tuna, J. Biol. Chem., 2010, 285, 18134-18138.

${ }_{78} 4$ M. Klein, L. Ouerdane, M. Bueno and F. Pannier, Identification in human urine and blood of a novel selenium metabolite, Semethylselenoneine, a potential biomarker of metabolization in mammals of the naturally occurring selenoneine, by HPLC coupled to electrospray hybrid linear ion trap-orbital ion trap MS, Metallomics, 2011, 3, 513-520.

${ }_{84} 5$ M. Yamashita, Y. Yamashita, T. Ando, J. Wakamiya and S. Akiba, Identification and determination of selenoneine, 2selenyl- $\mathrm{N}-\alpha, \mathrm{N}-\alpha, \mathrm{N}$ - $\alpha$-trimethyl-L-histidine, as the major organic selenium in blood cells in a fish-eating population on Remote Japanese Islands, Biol. Trace Elem. Res., 2013, 156, 36-44.

${ }_{90} 6$ Y. Yamashita, T. Yabu and M. Yamashita, Discovery of the strong antioxidant selenoneine in tuna and selenium redox metabolism, World J. Biol. Chem., 2010, 1, 144-150.

${ }_{93} 7$ M. Yamashita, Y. Yamashita, T. Suzuki, Y. Kani, N. Mizusawa, S. Imamura, K. Takemoto, T. Hara, M.A. Hossain, T. Yabu and K. Touhata, Selenoneine, a novel selenium-containing compound, mediates detoxification mechanisms against methylmercury accumulation and toxicity in zebrafish embryo, Mar. Biotechnol., 2013, 15, 559-570.

${ }_{99} 8$ Z. Pedrero Zayas, L. Ouerdane, S. Mounicou, R. Lobinski, M. Montperrus and D. Amouroux, Hemoglobin as a major binding protein for methylmercury in white-sided dolphin liver, Anal. Bioanal. Chem., 2014, 406, 1121-1129.

${ }_{103} 9$ H. Heath, A. Lawson and C. Rimington, Synthesis of ergothioneine, Nature, 1950, 166, 106.

10510 J.Z. Xu and J.C. Yadan, Synthesis of L-(+)-ergothioneine, J. Org. Chem., 1995, 60, 6296-6301.

${ }_{107} 11$ I. Erdelmeier, S. Daunay, R. Lebel, L. Farescour and J.C. Yadan, Cysteine as a sustainable sulfur reagent for the protectinggroup-free synthesis of sulfur-containing amino acids: biomimetic synthesis of L-ergothioneine in water, Green Chem., 2012, 14, 2256-2265.

${ }_{12} 12$ Y. Li, Y. Liu, X. Xiong, F. Li and P. Wei, Chemical synthesis method of novel natural antioxidant selenoneine, CN Patent Application, 2013, CN104072423A.

13 T. Pluskal, M. Ueno and M. Yanagida, Genetic and metabolomic dissection of the ergothioneine and selenoneine biosynthetic pathway in the fission yeast, S. pombe, and construction of an overproduction system, PLOS ONE, 2014, 9, e97774.

2014 K. Ichikawa, Y. Shinohara, S. Hara, K. Kurosawa, Y. Yamashita and M. Yamashita, Method for producing selenoneine, WO Patent Application, 2017, WO2017026173A1. 
${ }_{1} 15$ S. L. Forsburg and N. Rhind, Basic methods for fission yeast, Yeast, 2006, 23, 173-183.

${ }_{3} 16$ L.A. Wessjohann, A. Schneider, M. Abbas and W. Brandt, Selenium in chemistry and biochemistry in comparison to sulfur, Biol. Chem., 2007, 388, 997-1006.

${ }_{617}$ S. Kokarnig, A. Tsirigotaki, T. Wiesenhofer, V. Lackner, K.A. Francesconi, S. Pergantis and D. Kuehnelt, Concurrent quantitative HPLC-mass spectrometry profiling of small selenium species in human serum and urine after ingestion of selenium supplements, J. Trace Elem. Med. Biol., 2015, 29, 8390.

${ }_{12} 18$ N. Kroepfl, K.B. Jensen, K.A. Francesconi and D. Kuehnelt, Human excretory products of selenium are natural constituents of marine fish muscle, Anal. Bioanal. Chem., 2015, 407, 7713-7719.

$1619 \mathrm{~J}$. Petersen and P. Russell, Growth and the environment of 17 Schizosaccharomyces pombe. Cold Spring Harb Protoc., 2016, $18 \quad 3$, pdb.top079764. 


\section{Electronic Supplementary Information}

\section{Biosynthesis and Isolation of Selenoneine from Genetically Modified Fission Yeast}

Nikolaus G. Turrini, Nina Kroepfl, Kenneth B. Jensen, Tamara C. Reiter, Kevin A. Francesconi, Tanja Schwerdtle, Wolfgang Kroutil and Doris Kuehnelt

Table S-1: Chromatographic conditions for selenium species determination and clean-up of selenoneine from S. pombe TP1803

Figure S-1: Typical HPLC/ICPMS chromatogram $\left({ }^{78} \mathrm{Se}\right)$ of a lysate of $S$. pombe grown in selenatecontaining medium; Chromatographic conditions: Column: Atlantis dC18, $4.6 \times 150 \mathrm{~mm}$, column temperature: $30{ }^{\circ} \mathrm{C}$, mobile phase: $3 \%$ aqueous methanol, flow rate: $1 \mathrm{~mL} \mathrm{~min}{ }^{-1}$, injection volume: 1 $\mu \mathrm{L}$.

Figure S-2: Typical anion-exchange HPLC/ICPMS chromatogram $\left({ }^{78} \mathrm{Se}\right)$ of a lysate of S. pombe grown in selenate-containing medium; native lysate (solid line) and lysate spiked with $150 \mu \mathrm{g} \mathrm{Se} \mathrm{L}^{-1}$ selenite and selenate (dashed line); insert shows the full chromatogram; Chromatograpic conditions: Column: Dionex lonPac ${ }^{\mathrm{TM}}$ AS14A-5 $\mu \mathrm{m} \mathrm{RFIC}^{\mathrm{TM}} 3 \times 150 \mathrm{~mm}$, column temperature: $40{ }^{\circ} \mathrm{C}$, mobile phase: $5 \mathrm{mM}$

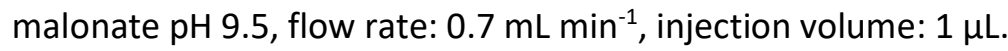

Figure S-3: HPLC/ICP-QQQ-MS chromatogram (oxygen mode, ca $0.3 \mathrm{~mL} \mathrm{O}_{2} \mathrm{~min}^{-1}$; mass shift ${ }^{78} \mathrm{Se} \rightarrow{ }^{78} \mathrm{Se}^{16} \mathrm{O}$ and ${ }^{32} \mathrm{~S} \rightarrow{ }^{32} \mathrm{~S}^{16} \mathrm{O}$ ) of a lysate of $\mathrm{S}$. pombe grown in selenate-containing medium; Chromatographic conditions: Column: Atlantis $\mathrm{dC} 18,4.6 \times 150 \mathrm{~mm}$, column temperature: $30{ }^{\circ} \mathrm{C}$, mobile phase: $3 \%$ aqueous methanol, flow rate: $1 \mathrm{~mL} \mathrm{~min}^{-1}$, injection volume: $1 \mu \mathrm{L}$.

Figure S-4: Flow injection ESI-Orbitrap-MS of fraction 2 obtained after cleanup-step 1 (NEUTRAL 1, Supplementary Material Table S1-B) of a lysate of $S$. pombe grown in selenate-containing medium directly treated with $\mathrm{H}_{2} \mathrm{O}_{2}$ before clean-up resulting in the formation of the mixed oxidised S-Se-species and oxidised ergothioneine; (a) spectrum of the mixed oxidised S-Se-species, (b) calculated isotope pattern for the mixed oxidised S-Se-species, (c) spectrum of oxidised ergothioneine, (d) calculated isotope pattern for oxidised ergothioneine; mobile phase: $3 \%$ aqueous methanol; flow rate: $0.4 \mathrm{~mL}$ $\min ^{-1}$, injection volume: $1 \mu \mathrm{L}$.

Figure S-5: HPLC/ICPMS chromatogram $\left({ }^{78} \mathrm{Se}\right)$ of a lysate of S. pombe grown in selenate-containing medium before (a) and after (b) rinsing of the HPLC system with $0.15 \% \mathrm{H}_{2} \mathrm{O}_{2}$; Chromatographic conditions: Column: Atlantis dC18 OBT, $19 \times 100 \mathrm{~mm}$, column temperature: ambient, mobile phase: $3 \%$ aqueous methanol, flow rate: $5 \mathrm{~mL} \mathrm{~min}^{-1}$, injection volume: $100 \mu \mathrm{L}(\mathrm{a}), 200 \mu \mathrm{L}$ (b).

Figure S-6: HPLC/ICPMS chromatogram $\left({ }^{78} \mathrm{Se}\right)$ of a lysate of S. pombe grown in selenate-containing medium applying a methanol gradient; Chromatographic conditions: Column: Atlantis dC18 OBT, $19 \times 100 \mathrm{~mm}$, column temperature: ambient, solvent gradient from $3 \%$ aqueous methanol to $30 \%$ aqueous methanol (for gradient details see Table S-1B, Clean-up step NEUTRAL 1), flow rate: $5 \mathrm{~mL} \mathrm{~min}$ 1, injection volume: $100 \mu \mathrm{L}$; vertical bars indicate the collected fraction containing oxidised selenoneine. 
Figure S-7: HPLC/ICPMS chromatogram $\left({ }^{78} \mathrm{Se}(\mathrm{a})\right.$ and $\left.{ }^{34} \mathrm{~S}(\mathrm{~b})\right)$ of a lysate of $\mathrm{S}$. pombe grown in selenatecontaining medium after application of the first clean-up step (Table S-1B, Clean-up step NEUTRAL 1); Chromatographic conditions: Column: Atlantis $\mathrm{dC} 18,4.6 \times 150 \mathrm{~mm}$, column temperature: $30^{\circ} \mathrm{C}$, mobile phase: $3 \%$ aqueous methanol, flow rate: $1 \mathrm{~mL} \mathrm{~min}^{-1}$, injection volume: $1 \mu \mathrm{L}$.

Figure S-8: HPLC/UV chromatograms (wavelength $260 \mathrm{~nm}$ ) for monitoring of the clean-up of oxidized selenoneine from a lysate of $S$. pombe grown in selenate-containing medium using three consecutive preparative chromatographic steps (Table S1-B NEUTRAL 1 (a), ACIDIC (b), and NEUTRAL 2 (c); vertical bars indicate the collected fractions containing the oxidised selenoneine); Chromatographic conditions: Column: Atlantis dC18 OBT, $19 \times 100 \mathrm{~mm}$, column temperature: ambient, flow rate: $5 \mathrm{~mL}$ $\mathrm{min}^{-1}$, injection volume: $1200 \mu \mathrm{L}$. For mobile phases, solvent gradients, and collected fractions see Table S-1B.

Figure S-9: Flow injection ESI-Orbitrap-MS of an aqueous solution of oxidised selenoneine for monitoring of the clean-up from a lysate of $S$. pombe grown in selenate-containing medium using two consecutive preparative chromatographic steps (NEUTRAL 1 (a), ACIDIC (b), Fig. 2, Supplementary Table S1-B); mobile phase: $3 \%$ aqueous methanol; flow rate: $0.4 \mathrm{~mL} \mathrm{~min}^{-1}$, injection volume: $1 \mu \mathrm{L}$.

Figure S-10: ${ }^{1} \mathrm{H}-\mathrm{NMR}$ spectrum (a), Heteronuclear Single Quantum Coherence Spectroscopy (b), and Heteronuclear Multiple Bond Correlation (c) of the isolated oxidised selenoneine; frequency: $500-\mathrm{MHz}$, solvent: $\mathrm{D}_{2} \mathrm{O}$.

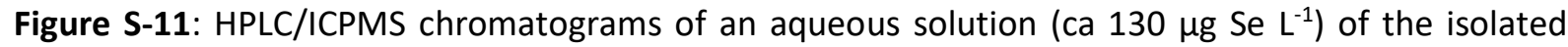
oxidised selenoneine; Chromatographic conditions: Column: Atlantis dC18, $4.6 \times 150 \mathrm{~mm}$, column temperature: $30{ }^{\circ} \mathrm{C}$, mobile phase: $3 \%$ aqueous methanol (a) or $20 \mathrm{mM}$ ammonium formate $3 \%$ methanol pH 3.0 (b), flow rate: $1 \mathrm{~mL} \mathrm{~min}^{-1}$, injection volume: $20 \mu \mathrm{L}$.

Figure S-12: HPLC/Orbitrap MS chromatograms ( $\mathrm{m} / \mathrm{z} 553.06$ and 278.04) of an aqueous solution (ca

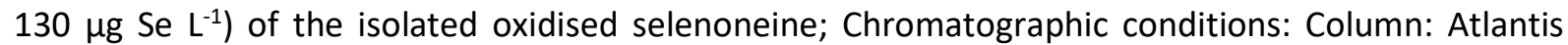
$\mathrm{dC} 18,4.6 \times 150 \mathrm{~mm}$, column temperature: $30{ }^{\circ} \mathrm{C}$, mobile phase: $3 \%$ aqueous methanol (a) or $20 \mathrm{mM}$ ammonium formate $3 \%$ methanol pH 3.0 (b), flow rate: $1 \mathrm{~mL} \mathrm{~min}{ }^{-1}$, injection volume: $20 \mu \mathrm{L}$.

Figure S-13: HPLC/ICPMS chromatogram of the isolated selenoneine; Chromatographic conditions: Column: Atlantis dC18, $4.6 \times 150 \mathrm{~mm}$, column temperature: $30^{\circ} \mathrm{C}$, mobile phase: $3 \%$ aqueous methanol (a) or $20 \mathrm{mM}$ ammonium formate $0.1 \mathrm{mM} \mathrm{TCEP} 3 \%$ methanol $\mathrm{pH} 3.0$ (b), flow rate: $1 \mathrm{~mL} \mathrm{~min}^{-1}$, injection volume: $20 \mu \mathrm{L}$. 
Table S-1: Chromatographic conditions for selenium species determination and clean-up of selenoneine from S. pombe TP1803

\section{A. Analytical reversed-phase HPLC}

\begin{tabular}{|c|c|c|c|}
\hline Column & \multicolumn{3}{|c|}{ Atlantis dC18, $4.6 \times 150 \mathrm{~mm}$ (Waters Corporation, Milford, USA) with guard column } \\
\hline Column temperature & $30^{\circ} \mathrm{C}$ & Flow rate & $1.0 \mathrm{~mL} \mathrm{~min}^{-1}$ \\
\hline \multicolumn{4}{|c|}{ 1. Speciation analysis of S. pombe cell lysates } \\
\hline Mobile phase & $\begin{array}{l}\text { A: water } \\
\text { B: methanol }\end{array}$ & $\begin{array}{l}\text { Injection volume } \\
D A D\end{array}$ & $\begin{array}{l}1 \mu \mathrm{L} \\
260 \mathrm{~nm}\end{array}$ \\
\hline Gradient & $\begin{array}{c}\text { Time }[\mathrm{min}] \\
0-20 \\
20-21 \\
21-27 \\
27-28 \\
28-35 \\
\end{array}$ & & $\begin{array}{c}\text { Eluent } B[\%] \\
3 \\
3-80 \\
80 \\
80-3 \\
3 \\
\end{array}$ \\
\hline $\begin{array}{l}\text { Position of 6-port-valve } \\
\text { between column and } \\
\text { ICPMS }\end{array}$ & $\begin{array}{c}0-20 \min \\
20-33 \min \\
33-35 \min \end{array}$ & \multicolumn{2}{|c|}{$\begin{array}{l}\text { position 1; effluent from column to ICPMS } \\
\text { position 2; effluent from column to waste } \\
\text { position 1; effluent from column to ICPMS }\end{array}$} \\
\hline \multicolumn{4}{|c|}{ 2. Determination of isolated product from S. pombe } \\
\hline Mobile phase & $\begin{array}{l}3 \% \mathrm{MeOH} \\
\text { or } 20 \mathrm{mM} \text { ammonium formate, } 3 \% \\
\text { methanol, } \mathrm{pH} 3 \text { (adjusted with } \\
\text { formic acid) } \\
\text { or } 20 \mathrm{mM} \text { ammonium formate, } 3 \% \\
\text { methanol, } 0.1 \mathrm{M} \mathrm{TCEP}, \mathrm{pH} 3 \\
\text { (adjusted with formic acid) }\end{array}$ & Injection volume & $1 \mu \mathrm{L}$ or $20 \mu \mathrm{L}$ \\
\hline \multicolumn{4}{|c|}{ B. Preparative reversed-phase HPLC } \\
\hline Column & \multicolumn{3}{|c|}{ Atlantis dC18 OBT, $19 \times 100 \mathrm{~mm}$ (Waters Corporation, Milford, USA) } \\
\hline Column temperature & & Injection volume & $1200 \mu \mathrm{L}$ \\
\hline Flow rate & $5.0 \mathrm{~mL} \mathrm{~min}^{-1}$ & $D A D$ & $260 \mathrm{~nm}$ \\
\hline \multicolumn{4}{|c|}{ 1. Clean-up step 1 (NEUTRAL 1) } \\
\hline Mobile phase & $\begin{array}{l}\text { A: water } \\
\text { B: methanol }\end{array}$ & & \\
\hline Gradient & $\begin{array}{l}\text { Time }[\mathrm{min}] \\
0-20 \\
20-21 \\
21-30 \\
30-31 \\
31-45 \\
\end{array}$ & & $\begin{array}{c}\text { Eluent } B[\%] \\
3 \\
3-30 \\
30 \\
30-3 \\
3 \\
\end{array}$ \\
\hline Fraction collection & $\begin{array}{l}24-25 \min \\
25-28 \min \\
28-30 \min \\
\end{array}$ & $\begin{array}{l}\text { Fraction } 1 \text { (F1); b } \\
\text { Fraction } 2 \text { (F2); c } \\
\text { Fraction } 3(\mathrm{~F} 3) ; \mathrm{a}\end{array}$ & $\begin{array}{l}\text { e target species } \\
\text { ining target species } \\
\text { target species }\end{array}$ \\
\hline \multicolumn{4}{|c|}{ 2. Clean-up step 2 (ACIDIC) } \\
\hline Mobile phase & $\begin{array}{l}\text { A: } 0.05 \% \mathrm{CH}_{3} \mathrm{COOH} \text { in water } \\
\text { B: methanol }\end{array}$ & & \\
\hline Gradient & $\begin{array}{c}\text { Time }[\mathrm{min}] \\
0-11 \\
11-12 \\
12-17 \\
17-18 \\
18-25 \\
\end{array}$ & & $\begin{array}{c}\text { Eluent } B[\%] \\
2 \\
2-50 \\
50 \\
50-2 \\
2 \\
\end{array}$ \\
\hline Fraction collection & $\begin{array}{c}7-8 \min \\
8-10 \min \\
10-11 \min \\
\end{array}$ & $\begin{array}{l}\text { Fraction } 1 \text { (F1); b } \\
\text { Fraction } 2 \text { (F2); c } \\
\text { Fraction } 3(\mathrm{~F} 3) ; \mathrm{a}\end{array}$ & $\begin{array}{l}\text { e target species } \\
\text { ining target species } \\
\text { target species }\end{array}$ \\
\hline \multicolumn{4}{|c|}{ 3. Clean-up step 3 (NEUTRAL 2) } \\
\hline \multicolumn{4}{|c|}{ Same settings as for clean-up step NEUTRAL 1 (see above), except for fraction collection } \\
\hline Fraction collection & $\begin{array}{l}24-25 \min \\
25-29 \min \\
29-31 \min \end{array}$ & $\begin{array}{l}\text { Fraction } 1 \text { (F1); b } \\
\text { Fraction } 2 \text { (F2); cc } \\
\text { Fraction } 3 \text { (F3); a }\end{array}$ & $\begin{array}{l}\text { e target species } \\
\text { ining target species } \\
\text { target species }\end{array}$ \\
\hline
\end{tabular}




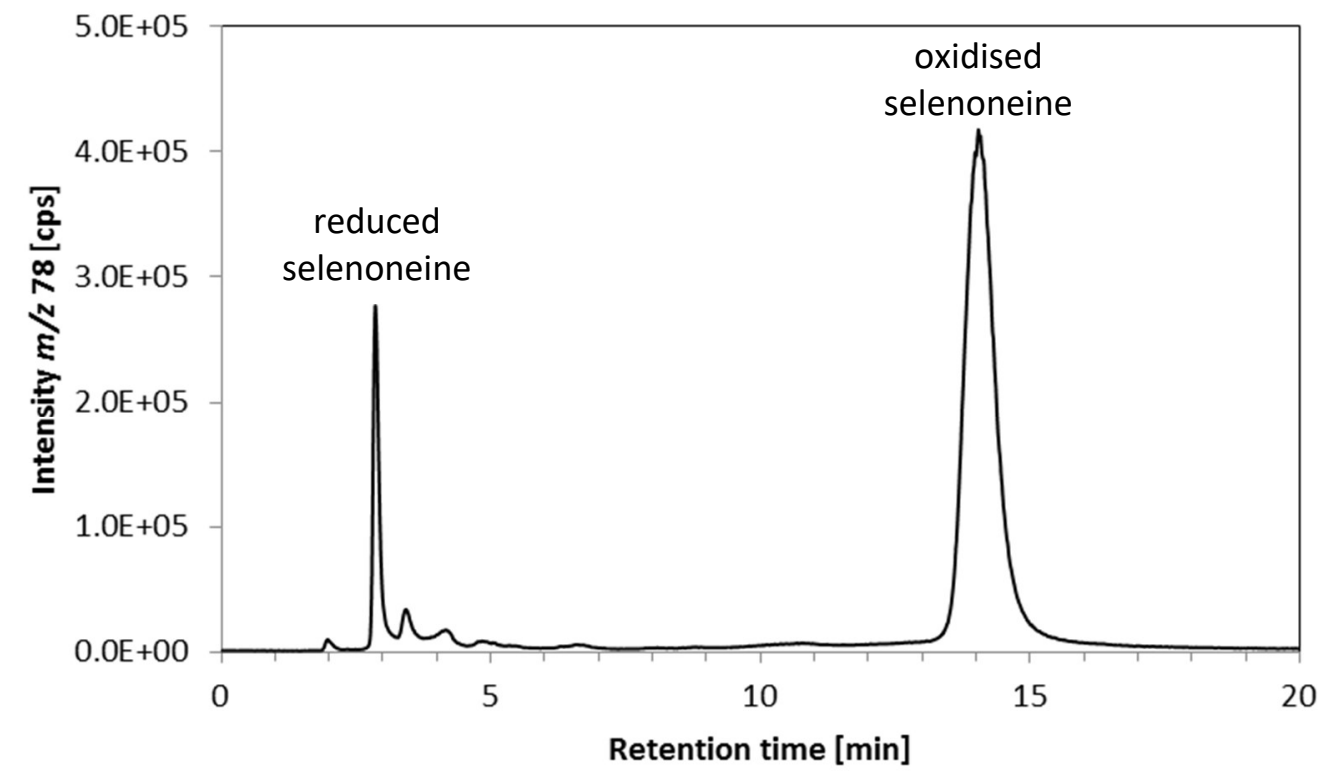

Figure S-1: Typical HPLC/ICPMS chromatogram ( ${ }^{78} \mathrm{Se}$ ) of a lysate of $S$. pombe grown in selenate-containing medium; Chromatographic conditions: Column: Atlantis dC18, $4.6 \times 150 \mathrm{~mm}$, column temperature: $30^{\circ} \mathrm{C}$, mobile phase: $3 \%$ aqueous methanol, flow rate: $1 \mathrm{~mL} \mathrm{~min}{ }^{-1}$, injection volume: $1 \mu \mathrm{L}$. 


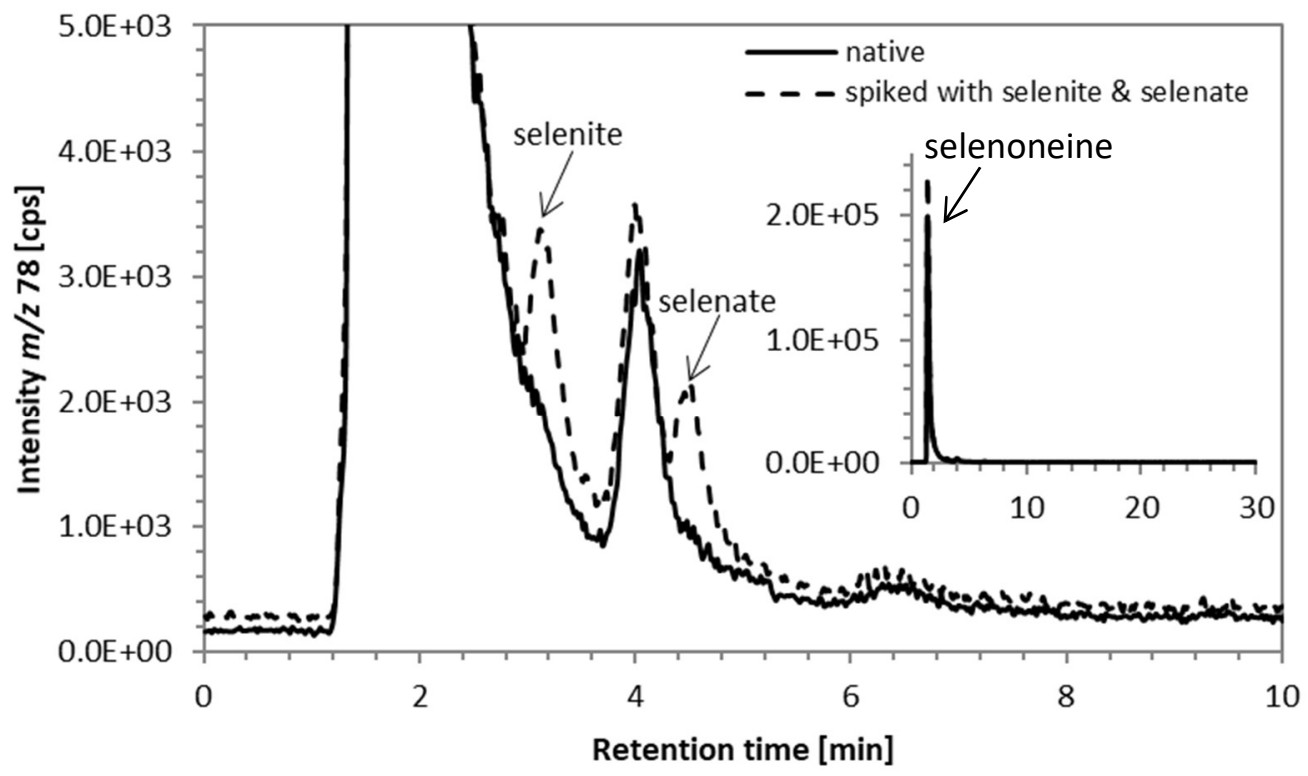

Figure S-2: Typical anion-exchange HPLC/ICPMS chromatogram ( $\left.{ }^{78} \mathrm{Se}\right)$ of a lysate of $S$. pombe grown in selenate-containing

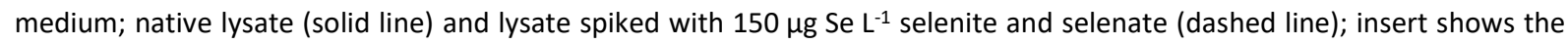
full chromatogram; Chromatograpic conditions: Column: Dionex lonPac ${ }^{\mathrm{TM}}$ AS14A-5 $\mu \mathrm{m}$ RFICTM $3 \times 150 \mathrm{~mm}$, column temperature: $40^{\circ} \mathrm{C}$, mobile phase: $5 \mathrm{mM}$ malonate $\mathrm{pH}$ 9.5, flow rate: $0.7 \mathrm{~mL} \mathrm{~min}^{-1}$, injection volume: $1 \mu \mathrm{L}$. 


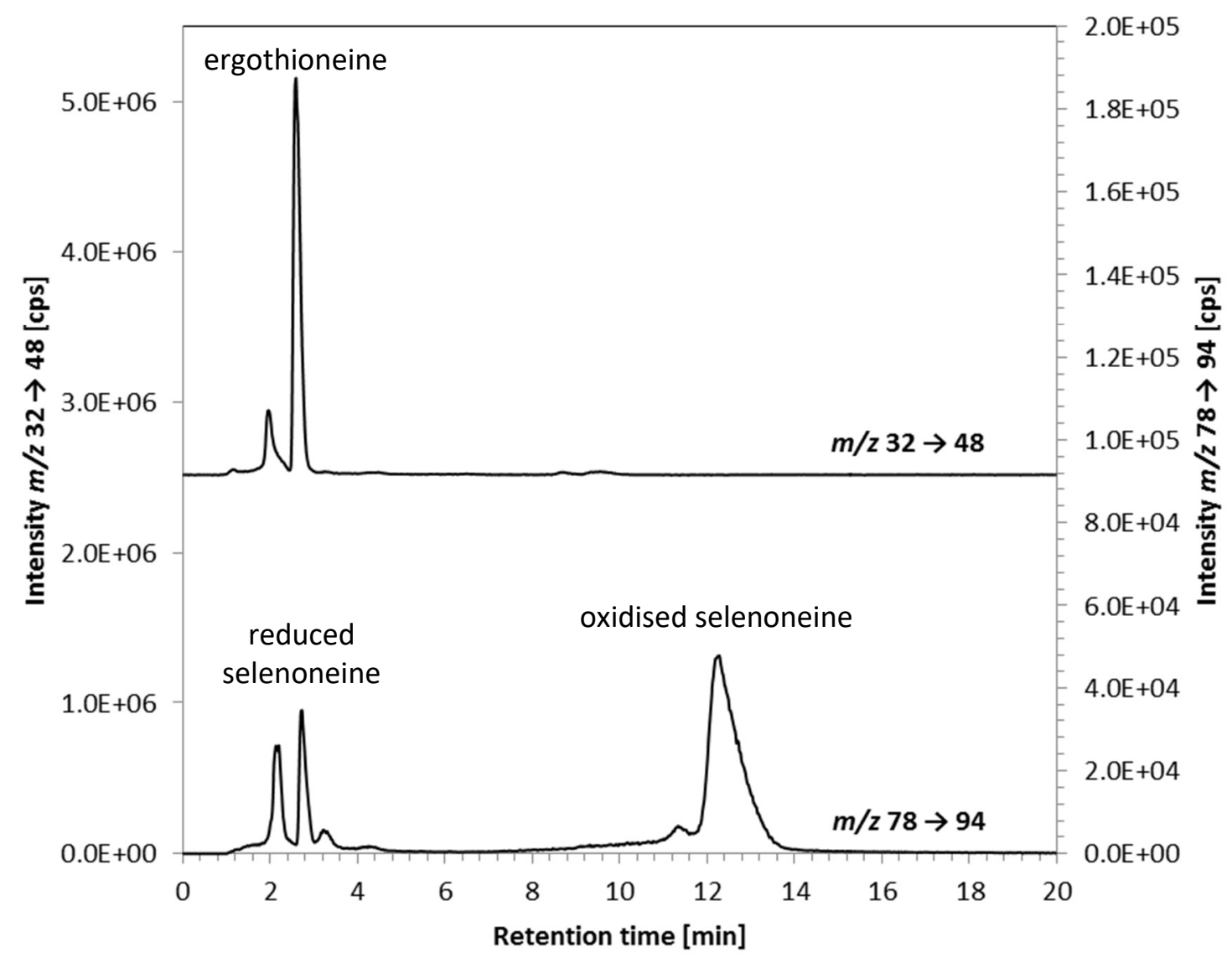

Figure S-3: HPLC/ICP-QQQ-MS chromatogram (oxygen mode, ca $0.3 \mathrm{~mL} \mathrm{O}_{2} \mathrm{~min}^{-1}$; mass shift ${ }^{78} \mathrm{Se} \rightarrow{ }^{78} \mathrm{Se}^{16} \mathrm{O}$ and ${ }^{32} \mathrm{~S} \rightarrow{ }^{32} \mathrm{~S}^{16} \mathrm{O}$ ) of a lysate of $S$. pombe grown in selenate-containing medium; Chromatographic conditions: Column: Atlantis dC18, $4.6 \times 150 \mathrm{~mm}$, column temperature: $30^{\circ} \mathrm{C}$, mobile phase: $3 \%$ aqueous methanol, flow rate: $1 \mathrm{~mL} \mathrm{~min}^{-1}$, injection volume: 1 $\mu \mathrm{L}$. 

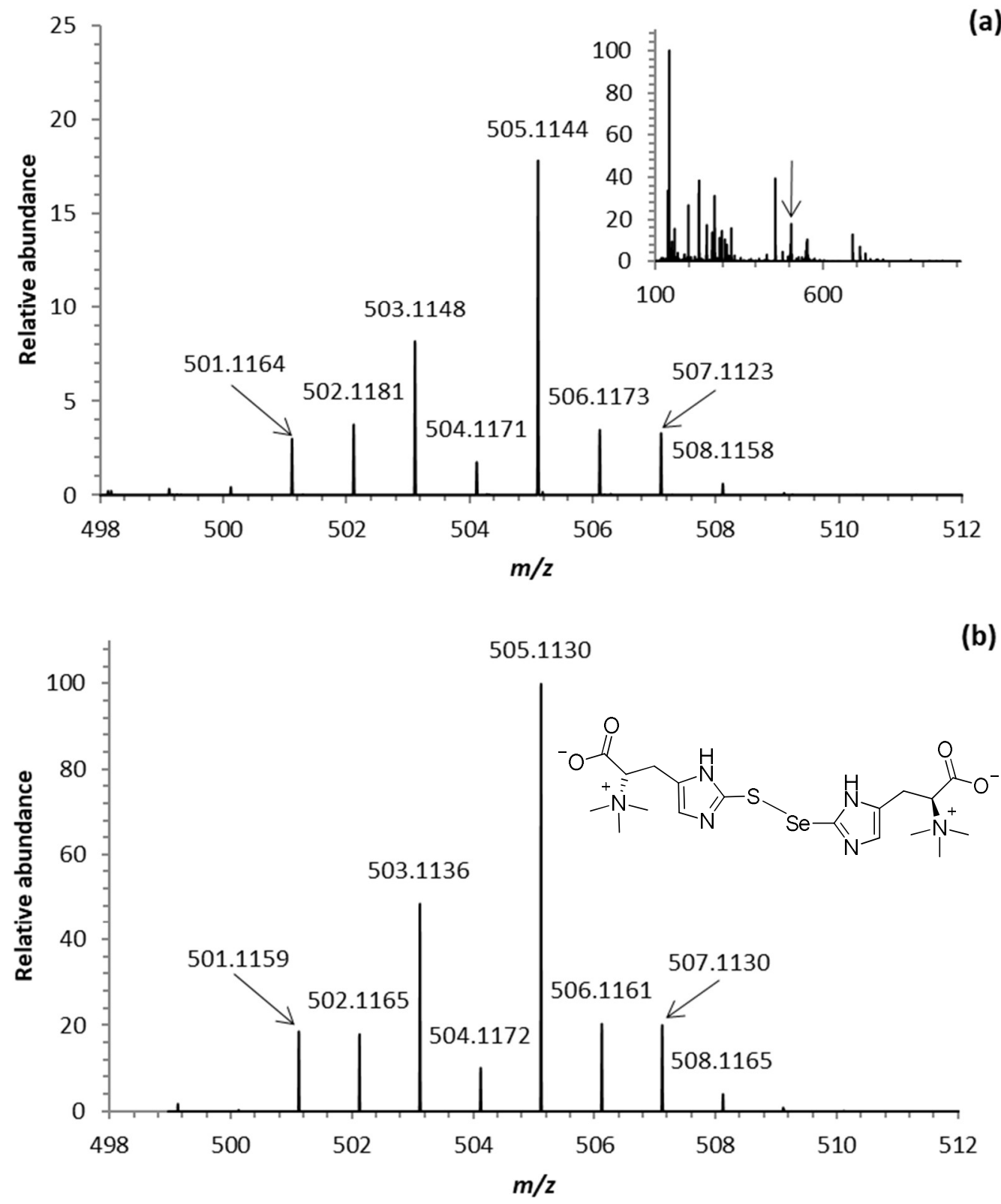

Figure S-4: Flow injection ESI-Orbitrap-MS of fraction 2 after cleanup-step 1 (NEUTRAL 1, Supplementary Material Table S1$B$ ) of a lysate of $S$. pombe grown in selenate-containing medium and treated by direct addition of $\mathrm{H}_{2} \mathrm{O}_{2}$ to the lysate; (a) spectrum of the mixed oxidised S-Se-species, (b) calculated isotope pattern for the mixed oxidised S-Se-species; mobile phase: $3 \%$ aqueous methanol; flow rate: $0.4 \mathrm{~mL} \mathrm{~min}^{-1}$, injection volume: $1 \mu \mathrm{L}$. 

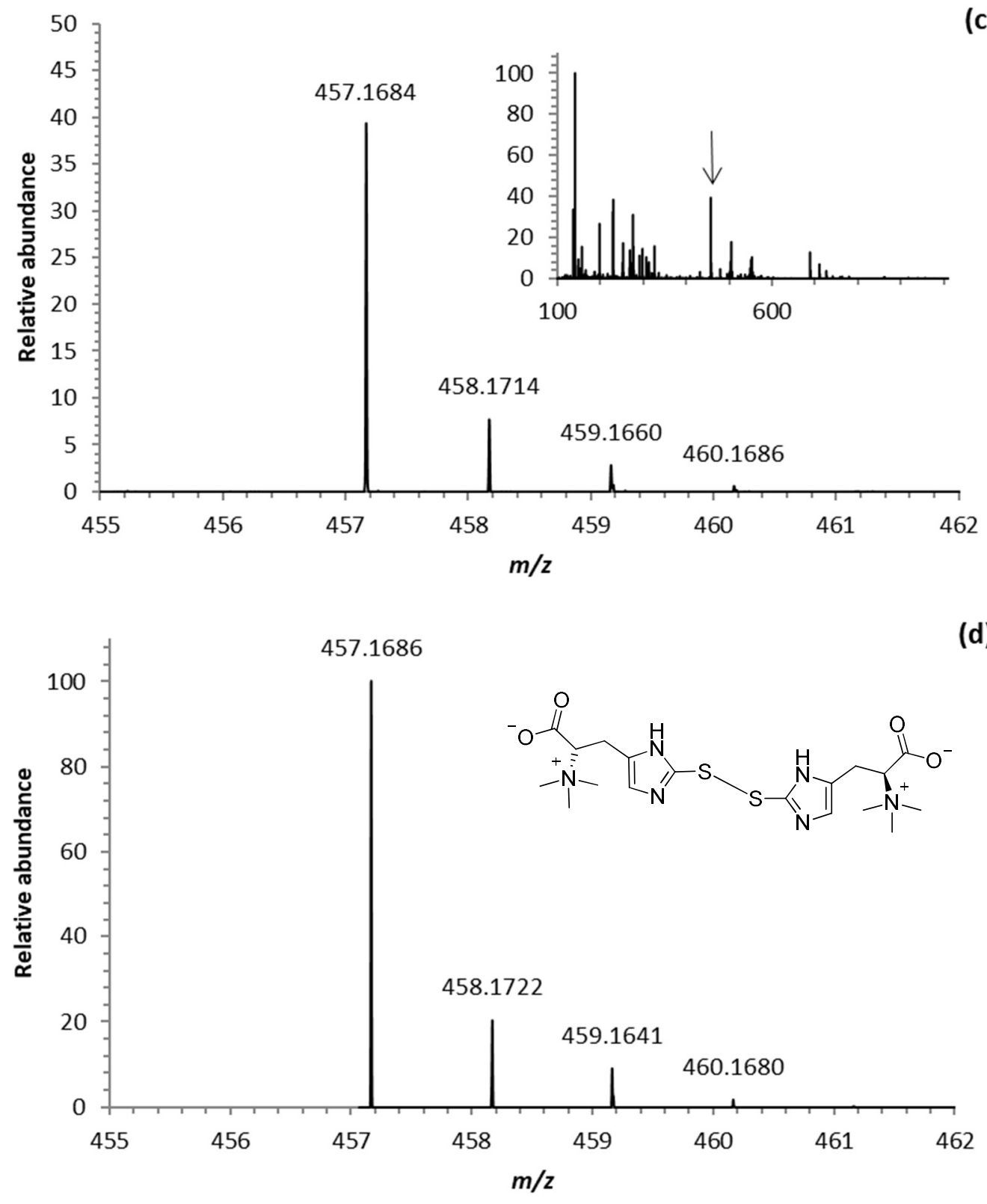

Figure S-4: Flow injection ESI-Orbitrap-MS of fraction 2 after cleanup-step 1 (NEUTRAL 1, Supplementary Material Table S1B) of a lysate of $S$. pombe grown in selenate-containing medium and treated by direct addition of $\mathrm{H}_{2} \mathrm{O}_{2}$ to the lysate; (c) spectrum of oxidised ergothioneine, (d) calculated isotope pattern for oxidised ergothioneine; mobile phase: $3 \%$ aqueous

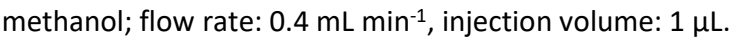



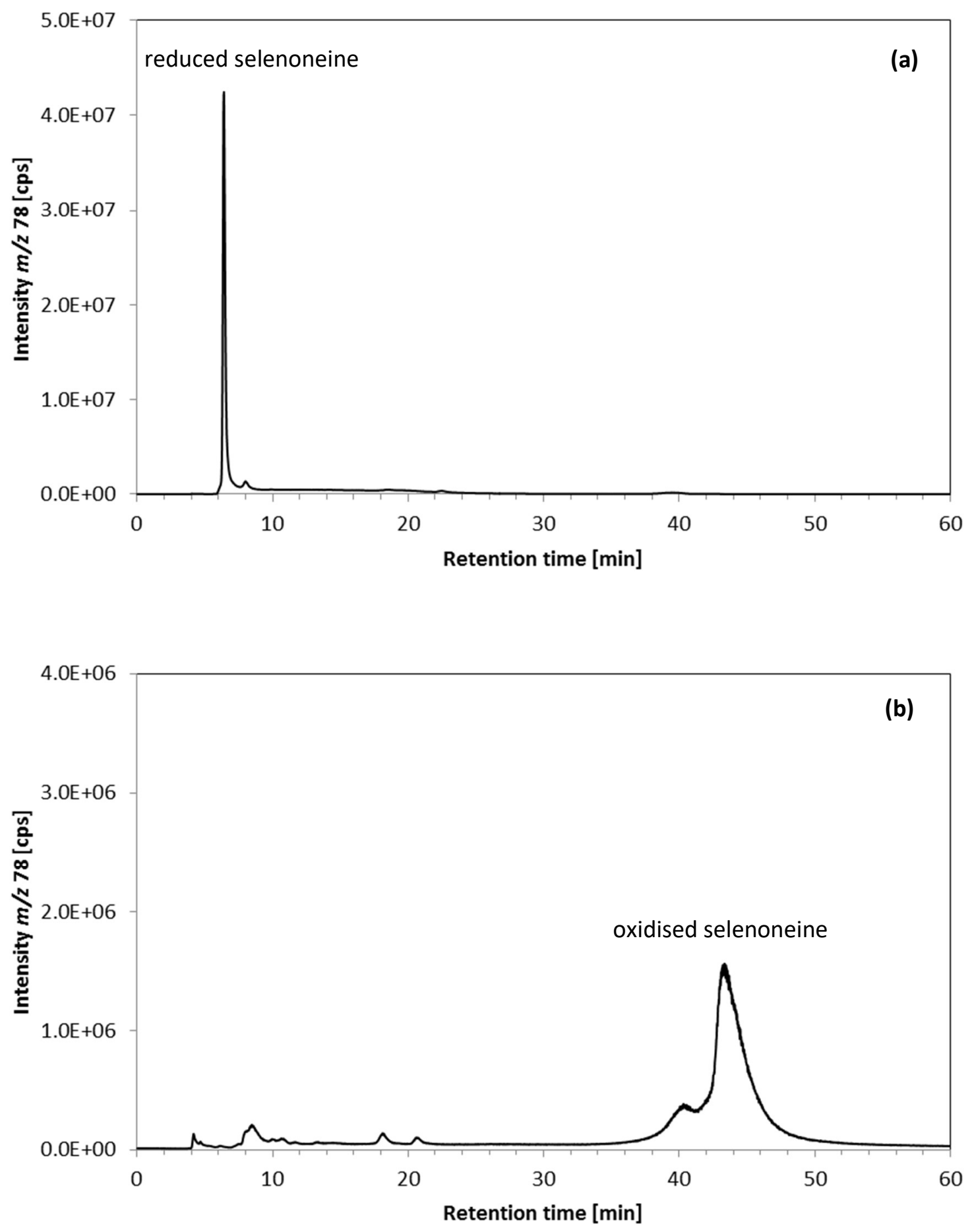

Figure S-5: HPLC/ICPMS chromatogram ( ${ }^{78} \mathrm{Se}$ ) of a lysate of $S$. pombe grown in selenate-containing medium before (a) and after (b) rinsing of the HPLC system with $0.3 \% \mathrm{H}_{2} \mathrm{O}_{2}$; Chromatographic conditions: Column: Atlantis dC18 OBT, $19 \times 100 \mathrm{~mm}$, column temperature: ambient, mobile phase: $3 \%$ aqueous methanol, flow rate: $5 \mathrm{~mL} \mathrm{~min}^{-1}$, injection volume: $100 \mu \mathrm{L}$ (a), 200 $\mu \mathrm{L}(\mathrm{b})$. 


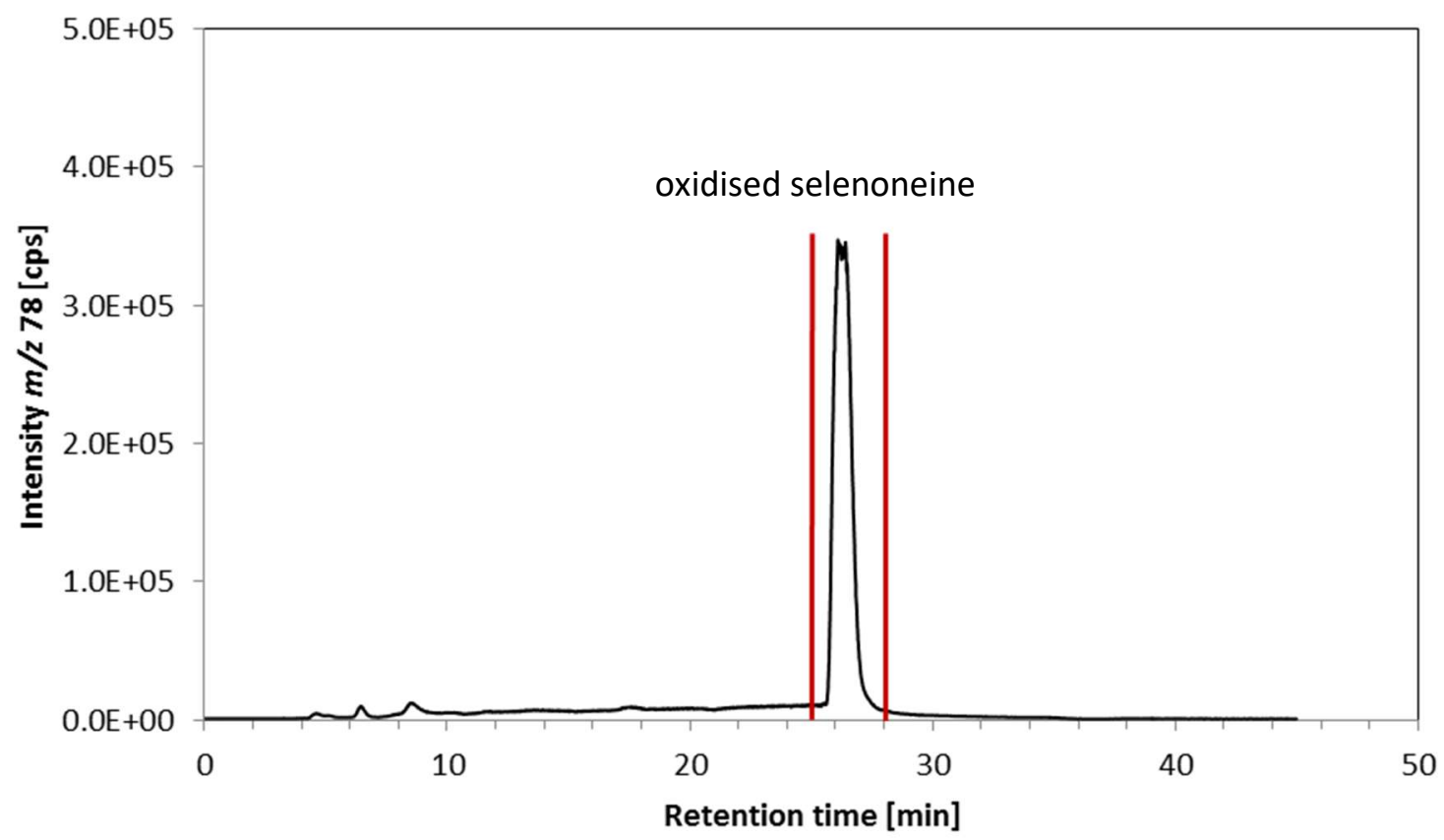

Figure S-6: HPLC/ICPMS chromatogram ( $\left.{ }^{78} \mathrm{Se}\right)$ of a lysate of S. pombe grown in selenate-containing medium applying a methanol gradient; Chromatographic conditions: Column: Atlantis dC18 OBT, $19 \times 100 \mathrm{~mm}$, column temperature: ambient, solvent gradient from $3 \%$ aqueous methanol to $30 \%$ aqueous methanol (for gradient details see Table S-1B, Clean-up step NEUTRAL 1), flow rate: $5 \mathrm{~mL} \mathrm{~min}{ }^{-1}$, injection volume: $100 \mu \mathrm{L}$; vertical bars indicate the collected fraction containing oxidised selenoneine. 

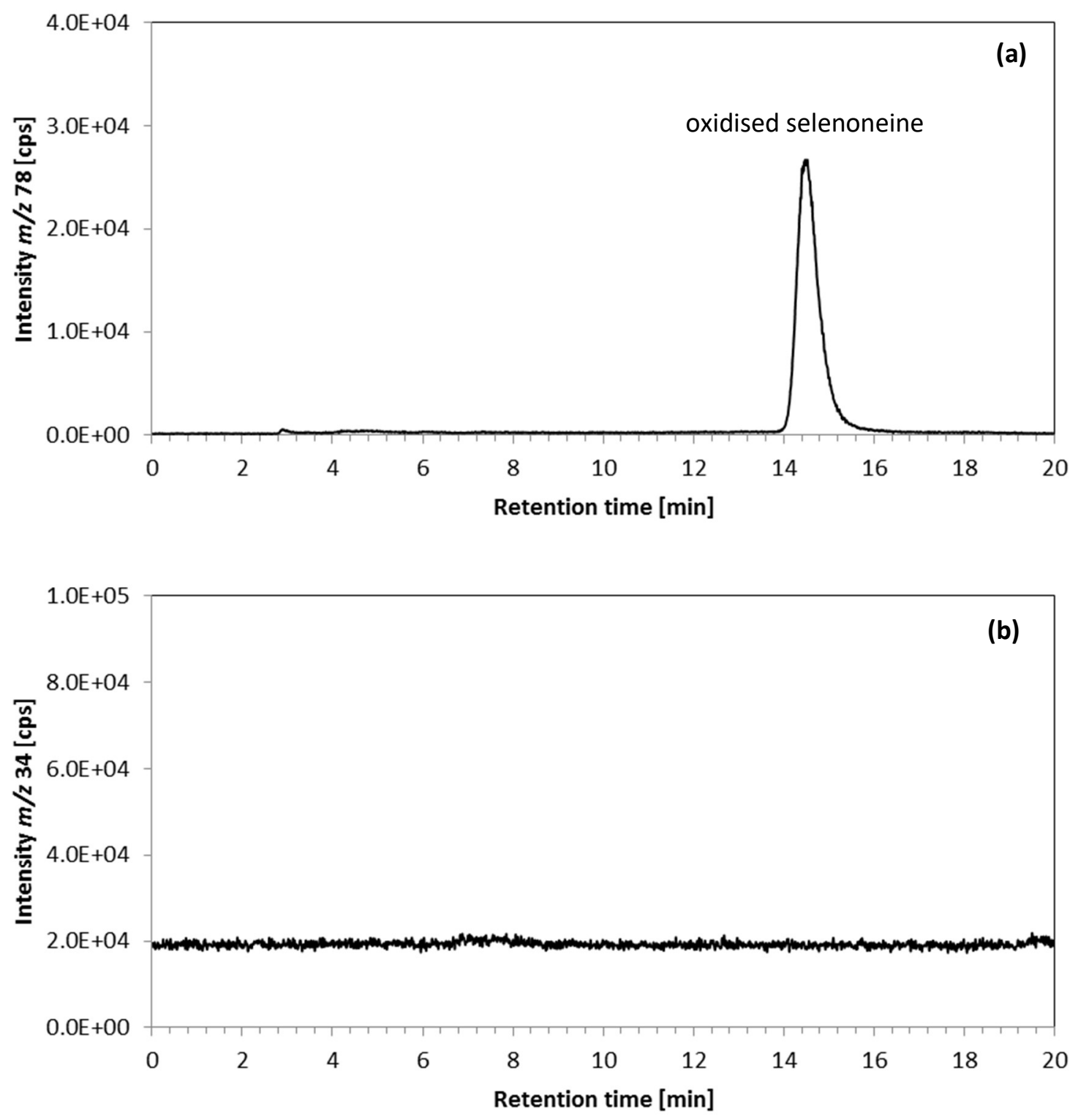

Figure S-7: HPLC/ICPMS chromatogram $\left({ }^{78} \mathrm{Se}(\mathrm{a})\right.$ and $\left.{ }^{34} \mathrm{~S}(\mathrm{~b})\right)$ of a lysate of $S$. pombe grown in selenate-containing medium after application of the first clean-up step (Table S-1B, Clean-up step NEUTRAL 1); Chromatographic conditions: Column: Atlantis $\mathrm{dC} 18,4.6 \times 150 \mathrm{~mm}$, column temperature: $30^{\circ} \mathrm{C}$, mobile phase: $3 \%$ aqueous methanol, flow rate: $1 \mathrm{~mL} \mathrm{~min}^{-1}$, injection volume: $1 \mu \mathrm{L}$. 

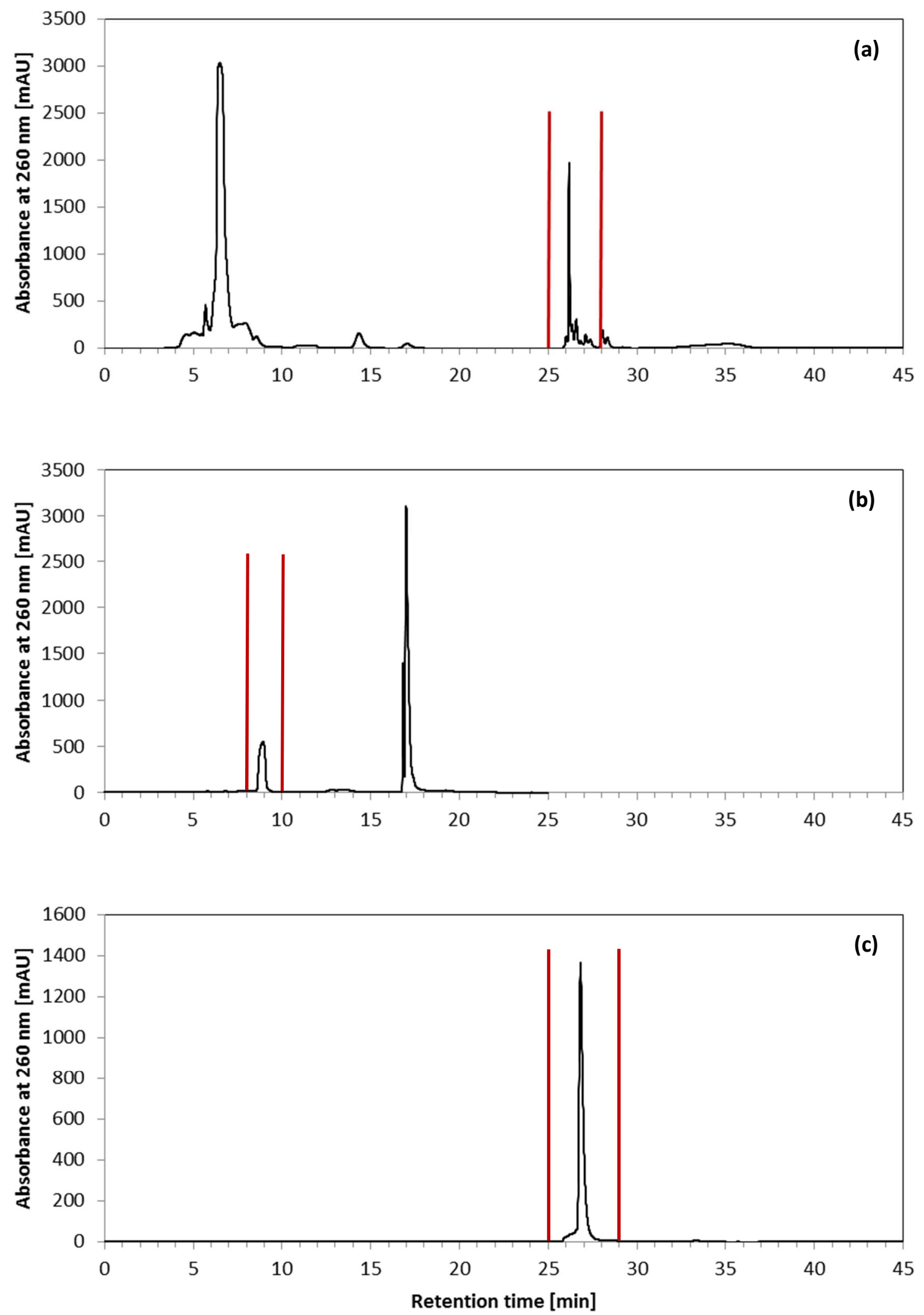

Figure S-8: HPLC/UV chromatograms (wavelength $260 \mathrm{~nm}$ ) for monitoring of the clean-up of oxidised selenoneine from a lysate of $S$. pombe grown in selenate-containing medium using three consecutive preparative chromatographic steps (Table S1-B NEUTRAL 1 (a), ACIDIC (b), and NEUTRAL 2 (c); vertical bars indicate the collected fractions containing the oxidised selenoneine); Chromatographic conditions: Column: Atlantis dC18 OBT, $19 \times 100 \mathrm{~mm}$, column temperature: ambient, flow rate: $5 \mathrm{~mL} \mathrm{~min}{ }^{-1}$, injection volume: $1200 \mu \mathrm{L}$. For mobile phases, solvent gradients, and collected fractions see Table S-1B. 

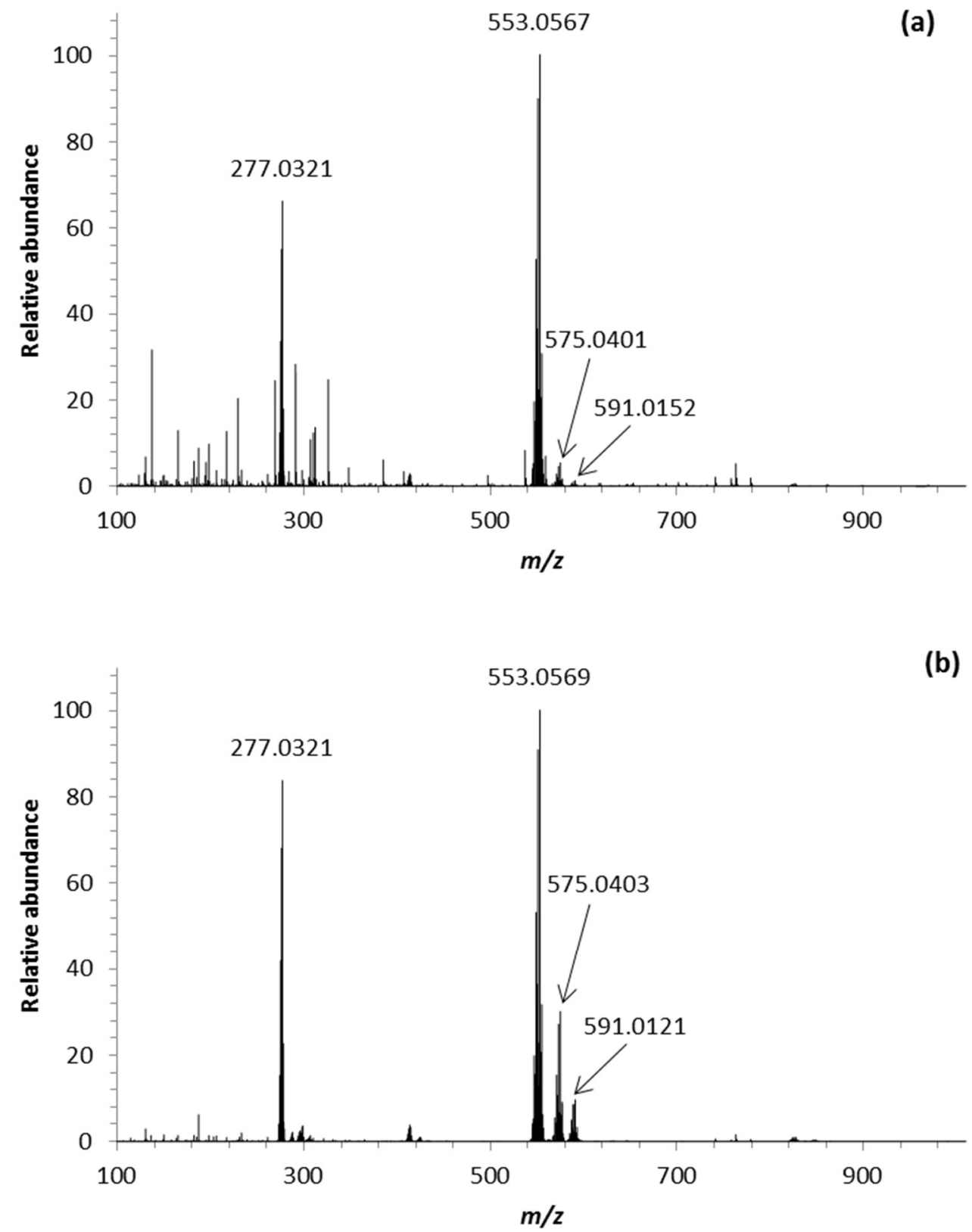

Figure S-9: Flow injection ESI-Orbitrap-MS of an aqueous solution of oxidised selenoneine for monitoring of the clean-up from a lysate of $S$. pombe grown in selenate-containing medium using two consecutive preparative chromatographic steps (NEUTRAL 1 (a), ACIDIC (b), Fig. 2, Supplementary Table S1-B); mobile phase: $3 \%$ aqueous methanol; flow rate: $0.4 \mathrm{~mL} \mathrm{~min}^{-1}$, injection volume: $1 \mu \mathrm{L}$. 


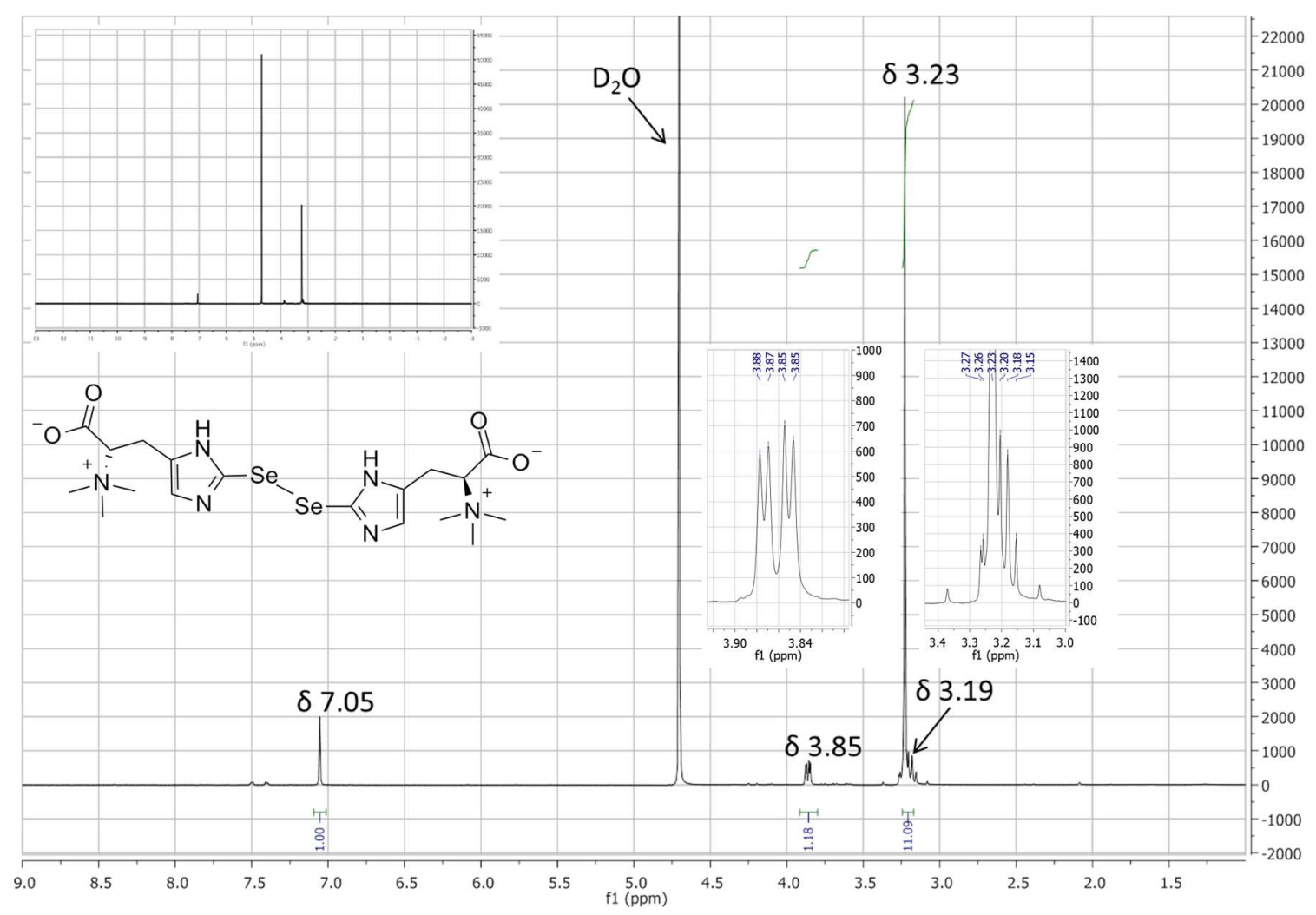

Figure S-10(a): ${ }^{1} \mathrm{H}-\mathrm{NMR}$ spectrum of the isolated oxidised selenoneine; frequency: $500-\mathrm{MHz}$, solvent: $\mathrm{D}_{2} \mathrm{O}$. 


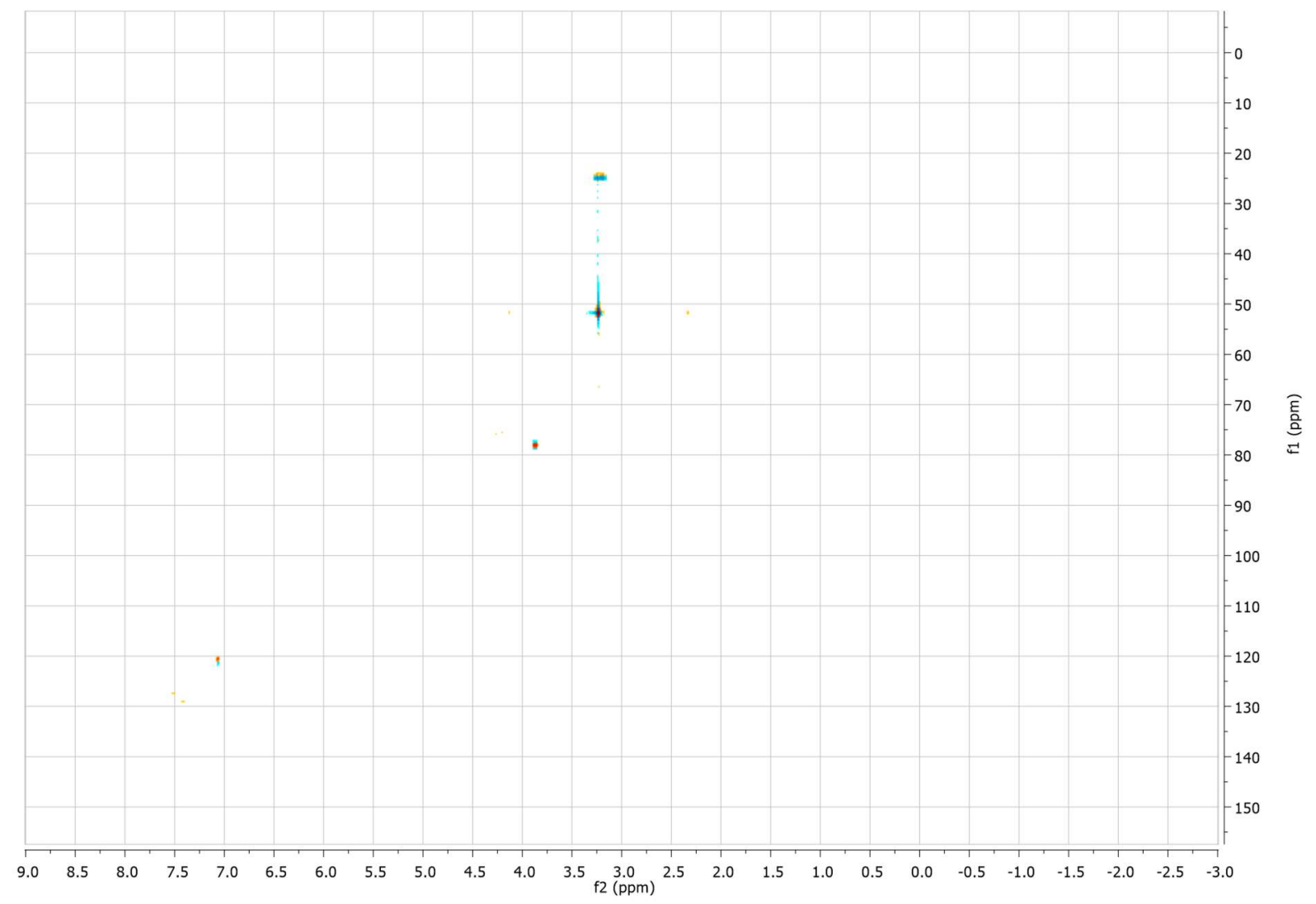

Figure S-10(b): Heteronuclear Single Quantum Coherence Spectroscopy of the isolated oxidised selenoneine; frequency: $500-$ $\mathrm{MHz}$, solvent: $\mathrm{D}_{2} \mathrm{O}$. 


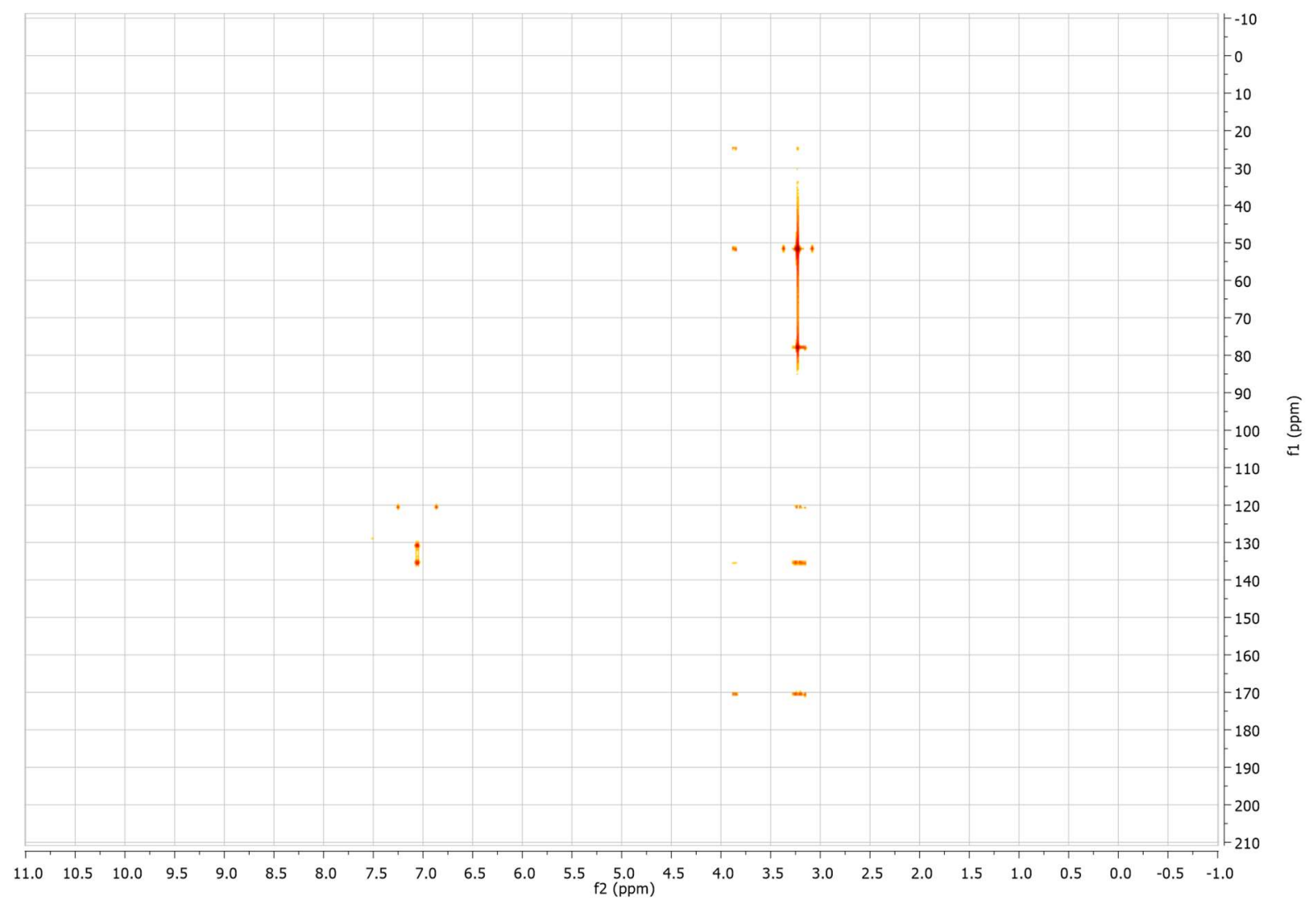

Figure S-10(c): Heteronuclear Multiple Bond Correlation of the isolated oxidised selenoneine; frequency: 500-MHz, solvent: $\mathrm{D}_{2} \mathrm{O}$. 

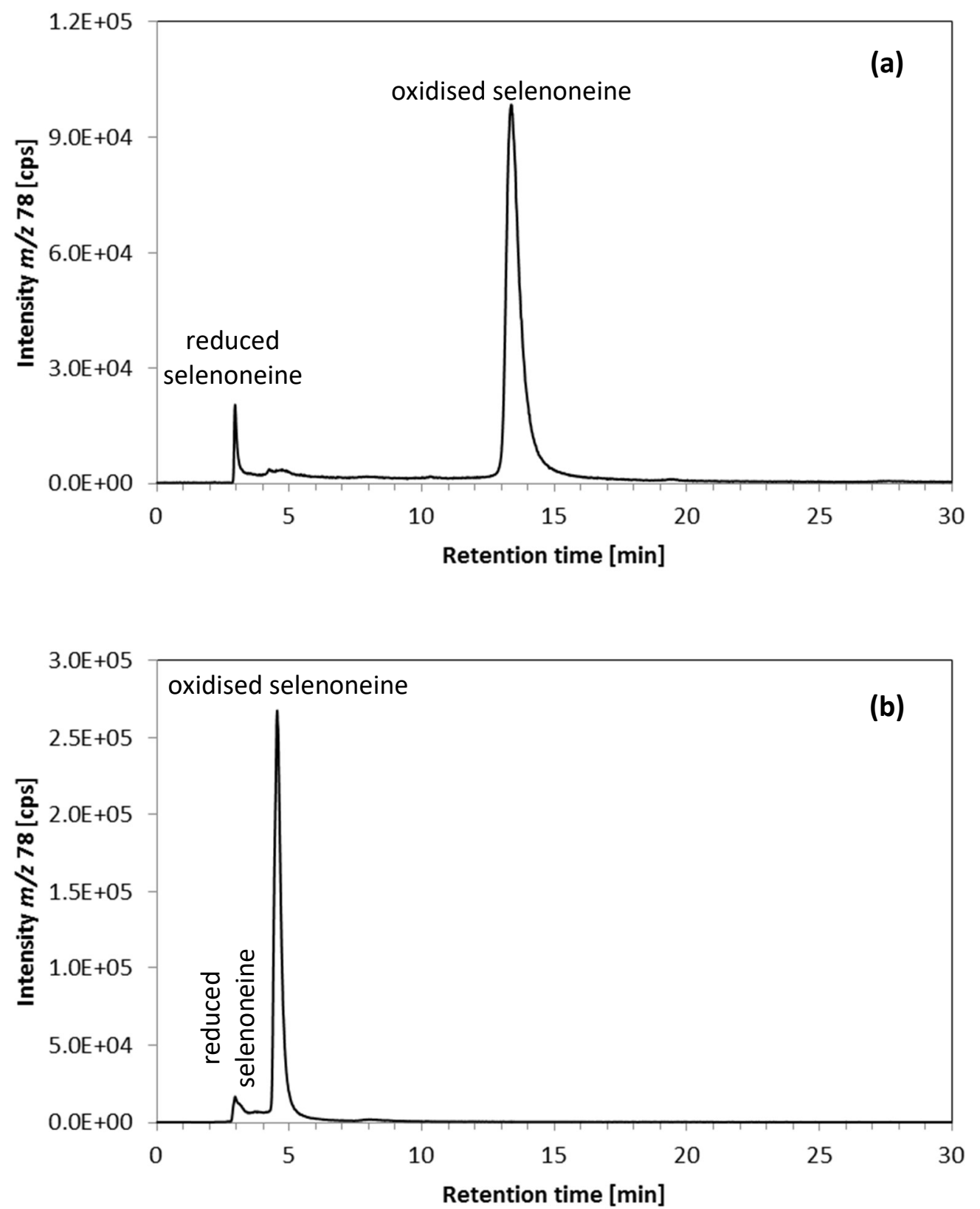

Figure S-11: HPLC/ICPMS chromatograms of an aqueous solution (ca $130 \mu \mathrm{g} \mathrm{Se}^{-1}$ ) of the isolated oxidised selenoneine; Chromatographic conditions: Column: Atlantis dC18, $4.6 \times 150 \mathrm{~mm}$, column temperature: $30^{\circ} \mathrm{C}$, mobile phase: $3 \%$ aqueous methanol (a) or $20 \mathrm{mM}$ ammonium formate $3 \%$ methanol pH 3.0 (b), flow rate: $1 \mathrm{~mL} \mathrm{~min}{ }^{-1}$, injection volume: $20 \mu \mathrm{L}$. 

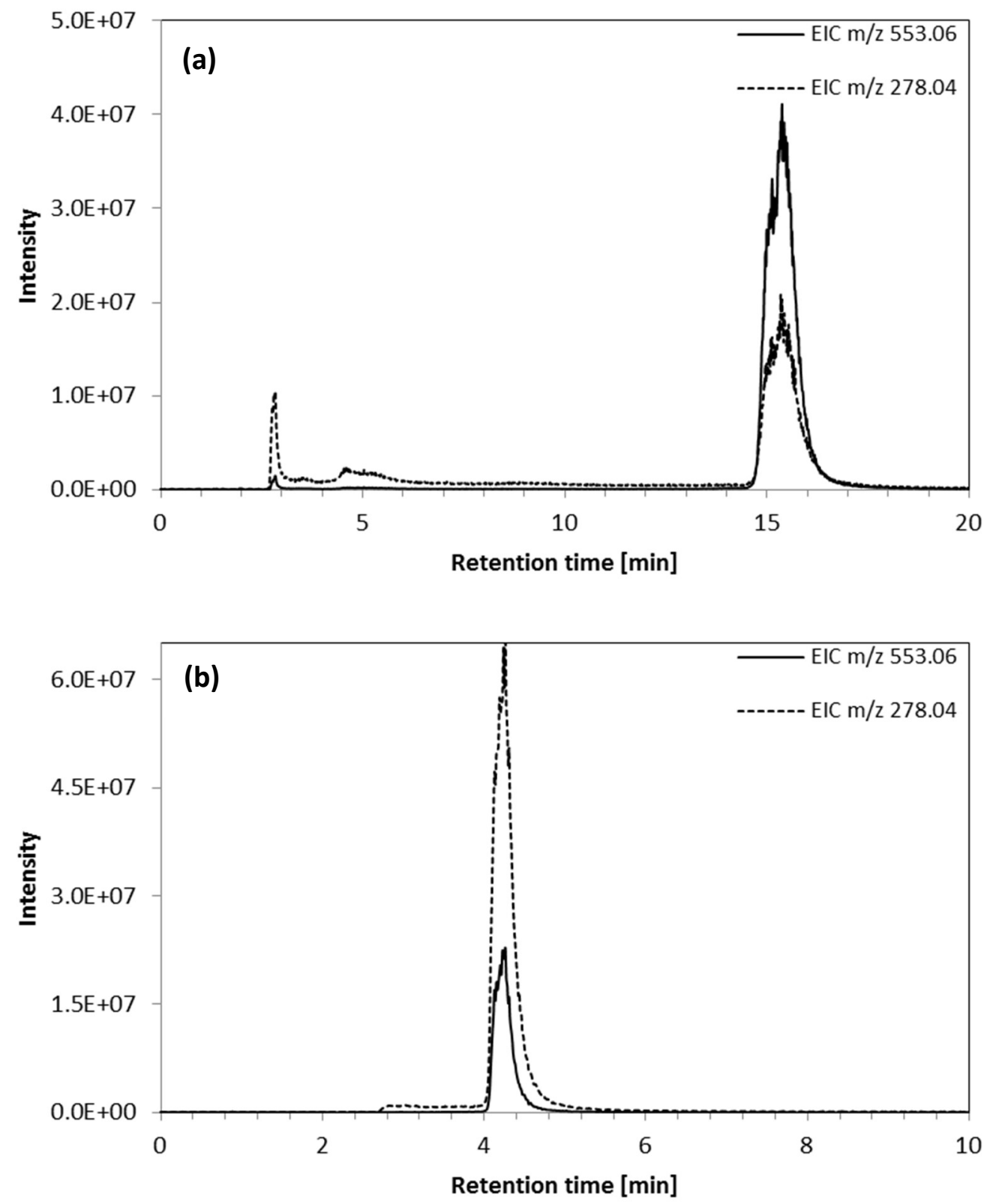

Figure S-12: HPLC/Orbitrap MS chromatograms ( $\mathrm{m} / \mathrm{z} 553.06$ and 278.04) of an aqueous solution (ca $130 \mu \mathrm{g} \mathrm{Se} \mathrm{L}^{-1}$ ) of the isolated oxidised selenoneine; Chromatographic conditions: Column: Atlantis dC18, $4.6 \times 150 \mathrm{~mm}$, column temperature: $30{ }^{\circ} \mathrm{C}$, mobile phase: $3 \%$ aqueous methanol (a) or $20 \mathrm{mM}$ ammonium formate $3 \%$ methanol pH 3.0 (b), flow rate: $1 \mathrm{~mL} \mathrm{~min}^{-1}$, injection volume: $20 \mu \mathrm{L}$. 


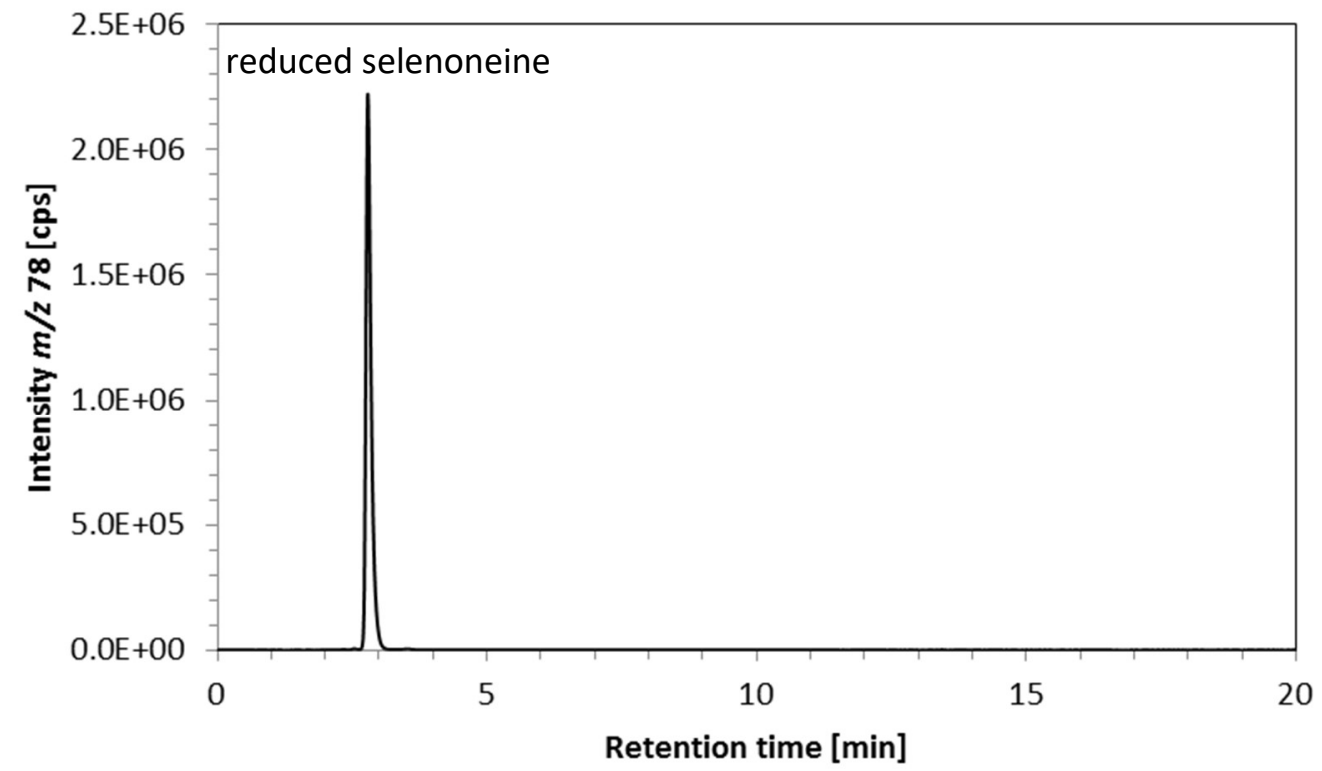

Figure S-13: HPLC/ICPMS chromatogram of the isolated selenoneine; Chromatographic conditions: Column: Atlantis dC18, $4.6 \times 150 \mathrm{~mm}$, column temperature: $30^{\circ} \mathrm{C}$, mobile phase: $3 \%$ aqueous methanol (A) or $20 \mathrm{mM}$ ammonium formate $0.1 \mathrm{mM}$ TCEP 3\% methanol pH 3.0 (B), flow rate: $1 \mathrm{~mL} \mathrm{~min}^{-1}$, injection volume: $20 \mu \mathrm{L}$. 